\title{
LA POLÍTICA EN EDUCACIÓN COMO DETERMINANTE DE DESARROLLO ECONÓMICO: EL CASO DE LA EDUCACIÓN DE MUJERES Y MENORES DE EDAD COMO VARIABLE PARA LA REDUCCIÓN DE LAS TASAS DE MORTALIDAD (II)*
}

\section{EDUCATION POLICY AS A DETERMINANT OF ECONOMIC DEVELOPMENT: THE CASE OF EDUCATION FOR WOMEN AND CHILDREN AS A VARIABLE TO REDUCE MORTALITY RATES (II)}

\author{
Luis Ricardo Gómez-Pinto** \\ Fecha de recepción: 12 de noviembre de 2013 \\ Fecha de aprobación: 9 de enero de 2014 \\ Disponible en línea: 30 de julio de 2014
}

\section{Para citar este artículo/To cite this article}

\begin{abstract}
Gómez-Pinto, Luis Ricardo, La política en educación como determinante de desarrollo económico: el caso de la educación de mujeres y menores de edad como variable para la reducción de las tasas de mortalidad (II), 129 Vniversitas, 135-186 (2014). http://dx.doi.org/10.11144/Javeriana.VJ129.pecd doi:10.11144/Javeriana.VJ129.pecd
\end{abstract}

* Este artículo comprende la segunda parte de la investigación realizada por la línea de investigación sobre política pública en el derecho social a la educación y desarrollo económico.

** Abogado, Pontificia Universidad Javeriana. Especialista en derecho sustantivo y contencioso constitucional y magíster en derecho económico. Profesor de derecho económico en la Facultad de Ciencias Jurídicas, Pontificia Universidad Javeriana y miembro del grupo de investigación de Derecho Público. Correo electrónico: 1.gomezp@javeriana.edu.co 


\section{RESUMEN}

La primera parte de esta investigación, publicada anteriormente, planteó la tensión histórica, como marco de la evolución de la política pública en educación en Colombia. Esta segunda parte contextualizará la crisis que afrontan los modelos educativos, como resultado de la contradicción que surge cuando se habla de modelos de desarrollo y modelos de crecimiento económico, como resultado de esa tensión histórica. Para desarrollar esta idea, el primer punto parte de la tesis de Amartya Sen sobre los bienes semipúblicos como respuesta a las crisis económicas en política educativa, que se materializan en las acciones afirmativas en educación de mujeres y niños. El segundo punto analizará los resultados en inversión en políticas educativas en el mundo, como el fomento para la ruptura de las brechas de segregación y las tasas de mortalidad. En la tercera parte, se hará una descripción de los principales retos que el proyecto educativo afronta desde la prevalencia de la postura del modelo de crecimiento, fortalecido por las reformas del siglo XXI. Al final, se arrojarán unas conclusiones generales de la investigación.

Palabras clave: derecho a la educación; economía liberal; economía social de mercado; modelo de desarrollo; bienes semipúblicos; crecimiento económico; acciones afirmativas; bienes y servicios esenciales; modelo intervencionista; derechos sociales fundamentales; Amartya Sen 


\section{ABSTRACT}

The first part of this research, published earlier, raised the historical tension of the evolution of public policy regarding education in Colombia. The second part, now in the reader's hands, contextualizes the crisis faced by education models, as a result of the contradiction that emerges when we talk about development models and models of economic growth, as a result of this historical tension. To develop this idea, the first point of the article is based on the theory of semi-public goods, explained by Amartya Sen, in response to the economic crisis in education policy, materialized through the response of affirmative actions in education for women and children. The second point analyzes the outcomes from the investments in education policy in the world, to promote the breakdown of the existing gaps of segregation and mortality rates. The third part of the paper describes the main challenges faced by the educational project due to the prevalence of the growth model, strengthened by reforms of the XXIst century. Finally, some general conclusions are presented.

Keywords: right to education; liberal economy; social economy; development economy; private and public goods; economic welfare; affirmative actions; social rights; Amartya Sen

\section{SUMARIO}

INTRODUCCIÓN: EL RETORNO DEL DOCTOR FRANKENSTEIN.- I. LA TEORÍA DE Amartya SEn SObre los bienes SEmipúblicos: LA RESPUESTA DE LAS ACCIONES AFIRMATIVAS A LA CRISIS ECONÓMICA EN EDUCACIÓN.- II. LA POLÍTICA DE INVERSIÓN EN EDUCACIÓN DE MUJERES Y NIÑOS COMO REDUCCIÓN DE LOS ÍNDICES DE MORTALIDAD E INEQUIDAD SOCIAL.- III. ESTRUCTURA DE LA POLÍTICA ECONÓMICA EN EDUCACIÓN A LA LUZ DE LAS REFORMAS CONSTITUCIONALES. Proyecto de Reforma eCONÓmica: 2001-2011.- A. Reforma al régimen de transferencias.- B. El principio de sostenibilidad fiscal.- IV. LA INTEGRACIÓN DE LAS POLÍTICAS COMO GARANTÍA PARA EL DESARROLLO. LA POLÍTICA LABORAL EN COLOMBIA COMO MEDICIÓN DEL VAlOR AGREGAdO EN EDUCACIÓN.- COMENTARIOS FINALES.- Bibliografía. 


\section{INTRODUCCIÓN: EL RETORNO DEL DOCTOR FRANKENSTEIN}

El principal objetivo de esta investigación es mostrar cómo el proceso de educación puede construir condiciones para reducir las tasas de mortalidad en mujeres, niños y jóvenes, al incrementar las capacidades, en el sentido que señala Amartya Sen, premio Nobel de Economía en 1998, de ingresar a los mercados como mecanismo para alcanzar la felicidad. En este sentido, y continuando la línea de la primera parte ${ }^{1}$, la propuesta se articula de la siguiente manera. En la primera parte, se hará un recuento de la teoría de los bienes semipúblicos que plantea Amartya Sen, partiendo del concepto de bienes primarios como garantías de libertades de las que hablaba John Rawls. Con esto se replanteará el clásico debate respecto a la gratuidad de la educación, cuando la Constitución y la teoría de los bienes semipúblicos parecen hablar de la postura contraria. El segundo punto tratará de dar un vistazo comparado de los resultados en inversión en políticas educativas en varios países, sobre la lógica de que las acciones afirmativas en materia de instrumentos de inversión en gasto público social permiten romper las brechas de segregación. En la tercera parte, se hará una descripción de los principales retos que afronta el proyecto educativo en Colombia desde la prevalencia de la postura del modelo de crecimiento que opta por la liberalización de mercados. Para esto, encontraremos cómo las fuerzas tradicionalistas del conservadurismo económico se apertrecharán en las reformas constitucionales del siglo XXI como herramienta para legitimar su proyecto. En la última parte, se hará una descripción de la educación como valor agregado para los mercados, las sociedades y los modelos constitucionales.

Finalmente, a modo de reflexión que se propone al lector, encontraremos cómo la tensión de los modelos económicos ${ }^{2}$ revive bajo el esquema de las reformas constitucionales que retornan al

1 En el artículo de mi autoría: Luis Ricardo Gómez-Pinto, La política en educación como determinante de desarrollo económico: el contexto histórico sobre la tensión de modelos económicos (I), 128 Vniversitas, 121-152 (2014), en adelante, Politica en educación. Disponible en: http:/l revistas.javeriana.edu.co/index.php/vnijuri/article/view/10171

2 La politica en educación, punto I.B: Un período coyuntural en la política económica para finales del siglo XX: la Constitución de 1991 y la educación en la economía social de mercado (2014). Disponible en: http://revistas.javeriana.edu.co/index.php/vnijuri/article/view/10171 
modelo clásico de mercado en oposición a la economía social. Se trata, a modo del doctor Frankenstein y su monstruo, en la obra de Mary W. Shelley, de las crisis económicas creadas por sus propias instituciones. Es un monstruo que ha creado otro, como resultado de su propia maldad. Aquí, advierte Sen, la respuesta del derecho se encaminará en búsqueda de la igualdad educativa y laboral como punto arquidémico de cambio social.

\section{La teoría de Amartya Sen sobre los bienes semipúblicos y la relación entre mercados y el derecho constitucional a la educación: la respuesta de las acciones afirmativas a la crisis económica en educación}

Para empezar, es necesario hacer una reflexión que se deberá tener en cuenta para el resto del trabajo. El discurso constitucional parte de dos elementos que se concilian en función del servicio a la educación como condición para garantizar el acceso a otros derechos. El derecho social a la educación requiere mercados que garanticen, no solo su oferta, sino condiciones efectivas que permitan el acceso de la demanda. Esta es la lógica de los mercados clásicos y es el supuesto mínimo del que parte la Constitución ${ }^{3}$ para garantizar la inclusión, el acceso y la calidad en la prestación del servicio. Lo particular de entender a la educación como un bien semipúblico, tal como lo denomina Sen, implica que se trata de un bien que a muchos no les interesa ofrecer. Esto, no obstante, desde la perspectiva de un diseñador de políticas públicas, justifica que el Estado tenga que intervenir el mercado, fijar las condiciones de incentivos para ofrecer el servicio que garantizará el derecho pero no necesariamente, partir de la gratuidad del servicio.

Hasta aquí, esta sería la respuesta que el derecho da a la interpretación del papel que juega la educación en la sociedad. Los economistas no parecen ponerse de acuerdo al definir cuál es la variable que permite identificar ese valor agregado y hacerlo cuantificable. Podríamos decir que el tratamiento al problema de la educación como variable de desarrollo no es pacífico. Aquí, ante la crisis de

3 Constitución Política, 4 de julio de 1991. Disponible en: http://www.alcaldiabogota.gov.co/ sisjur/normas/Norma1.jsp?i=4125 
los modelos económicos, los economistas contemporáneos regresan a las nociones de ética de la economía, para reformular la interpretación de las variables económicas en el desarrollo de los pueblos.

La crisis de las instituciones económicas y los avances y regresiones que la historia y los modelos económicos presentan, plantean una dicotomía entre definir la educación como un servicio público o entenderla como un derecho ${ }^{4}$. En este escenario, la discusión se hace más compleja cuando - para solucionar las limitaciones de los mercados - se recurre a una institución como los pactos constitucionales. Al entender la educación como un servicio público, como lo hace la Constitución, se entra en una esfera económica permeada por el derecho. El modelo liberal —identificado por los analistas y al que apuesta la Constitución-, que propone la apertura de mercados, tiene una finalidad. Su propuesta es que, mediante los mercados, concepción que data de $1950^{5}$, se permita el acceso a los bienes básicos por la propia interacción de los agentes del mercado. Estos bienes representan costos que se trasladan en precios. La lógica que permite la Constitución para la prestación de los servicios públicos habla de una estructura de mercado abierto a la libre competencia y la libertad económica, a la que entran quienes están dispuestos a ofrecer bienes con el fin de atender una demanda esperada. Hasta aquí, el modelo de la Constitución es clásico.

La Constitución apuesta por la perspectiva de mercados abiertos, con libertad de acceso y de iniciativa económica en materia de servicios públicos. En este sentido, el acceso a los mercados y la posibilidad de prestar un servicio público en condiciones de competencia, implica una responsabilidad social que vincula los servicios públicos esenciales como la educación. Los prestadores de servicios esenciales tienen la responsabilidad de prestar el servicio bajo condiciones de garantía mínima. Aquí se trata de una garantía social. Una de las condiciones esenciales que se deben garantizar es la libre disponibilidad del servicio y acceso. Esto es, la oferta debe ser eficiente, en el sentido de que haya una disponibilidad de

4 La política en educación, punto I.A: Discusiones sobre crecimiento y desarrollo en el modelo económico del siglo XX. 1936-2013 (2014). Disponible en: http://revistas.javeriana.edu.co/index. $\mathrm{php/vnijuri/article/view/10171}$

5 La política en educación, punto I.A: Discusiones sobre crecimiento y desarrollo en el modelo económico del siglo XX. 1936-2013 (2014). Disponible en: http://revistas.javeriana.edu.co/index. $\mathrm{php/vnijuri/article/view/10171}$ 
bienes que pueda cubrir la demanda esperada. Se trata, como lo considera Sen, de bienes primarios ${ }^{6}$ que responden a la interacción de oferentes y demandantes, respecto a cantidades ofrecidas y precio aceptables, en la cual el precio transmite las condiciones de ese acuerdo y el consenso de los intereses, lo que permite acceder a la atención de otros bienes esenciales que son incluso más importantes, para garantizar un proyecto de vida. De esta lógica parte la Constitución, porque confía en el equilibrio automático del mercado. Pero hay dos cosas que el mercado no puede prever y que pueden limitar la interacción de los agentes, incluso en el caso de servicios públicos esenciales. Una de ellas es el problema de la escasez del bien que se complementa con su naturaleza económica, a lo que el modelo liberal económico no parece responder con claridad. Si decimos que es un bien público, regresando a nuestra pregunta, se trataría claramente de un bien que ningún agente que reacciona a los incentivos estaría en condiciones de ofrecer porque no hay una contraprestación que retribuya los costos incurridos. La otra posibilidad que propone el modelo clásico es la que se trate de una externalidad positiva, como se mencionó en el punto anterior, en la cual hay un bien que no se ofrece de manera adecuada en el mercado, por lo cual requiere una medida de regulación que provea la cantidad faltante.

Sin embargo, tanto la primera como la segunda posibilidad deben ser descartadas. No se trata de un bien público, porque las condiciones de la existencia de un mercado del servicio de educación, en el cual los particulares y el Estado entran a competir para la prestación del servicio, hacen improbable esa definición porque sí hay una motivación para prestar el servicio. Sí se trata de un bien que se encuentra en el mercado y genera una rentabilidad. Respecto a lo segundo, tampoco se trata de una externalidad, porque la oferta puede alcanzarse mediante la regulación pero esto no representará un resultado medible como valor agregado en la economía.

No se trata de una limitación en las condiciones de oferta en el mercado; se trata de la existencia de barreras de acceso a él, lo que le resta eficiencia. Esto se demuestra en las tasas de deserción escolar, pero sobre todo en las barreras discriminatorias para el acceso de

6 Amartya K. Sen, La idea de la justicia, 284, Taurus, Bogotá (2010). 
grupos especiales de la población, como en el caso de las niñas en ciertas sociedades en las que se presta mayor atención a la educación de niños (figura 1). Aquí, el problema regresa a los clásicos. Se trata de precios que no reflejan la verdadera información de lo que pasa en el mercado. A esto debe agregarse otro problema. El valor que la educación representa para las partes no puede ser medido ni en el caso de tratarse de un bien en un mercado, ni en el caso de entenderse como una externalidad. El valor de la educación supera las perspectivas del mercado y es un valor adicional que no puede ser medido cuando se alcanza el efecto de la externalidad positiva por medio del subsidio, como generalmente se interviene para internalizar la externalidad y se alcance el valor social esperado, que es el cubrimiento de la demanda, como lo muestra la figura 1.

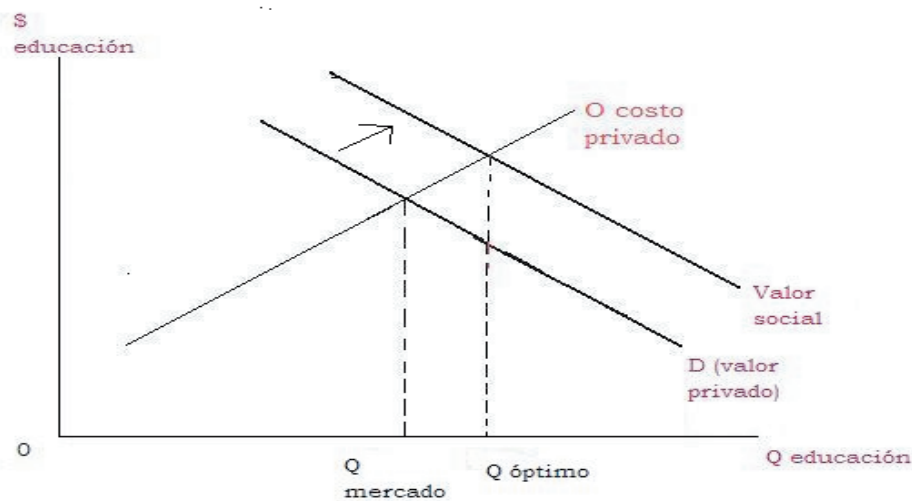

Figura 1

Externalidad en el mercado de la educación

Fuente: N. Gregory Mankiw, Principios de economía, capítulo 10, Las externalidades, 130, McGraw-Hill, Madrid (2004).

El servicio que garantiza el derecho a la educación puede funcionar en una lógica de mercados que no implica la gratuidad. Esto permite enfocar el análisis en la lógica de convivir con los supuestos básicos de la teoría del crecimiento a partir de los mercados, pero orientado a garantizar condiciones de desarrollo, que no se pueden medir, pero sí estimar por el valor social adicional que genera la educación cuando se interrelacione con otros sectores productivos, 
y se entienda como un bien semipúblico 7 . En parte, creemos que esta falta de poder de diagnóstico sobre el valor que encierra la educación, tiene qué ver con el papel que representa ella misma como un derecho con una valoración subjetiva que lo aleja de cualquier parámetro de medición ${ }^{8}$. Para que un mercado, como el de la educación, funcione de manera eficiente, pero sobre todo garantice condiciones de equidad en el acceso, no tiene que funcionar bajo un esquema de gratuidad que no garantizará condiciones de desarrollo9. Lo importante es enfocar la educación hacia modelos de desarrollo que hablan de la sostenibilidad de los derechos.

No creemos que se trate de una situación en la que los bienes meritorios o los derechos esenciales deban ser prestados en condiciones de gratuidad y necesariamente llevar a que el Estado asuma el 100\% de la carga. Se trata de que el sistema de precios del modelo clásico está en crisis y resulta limitado para las aspiraciones de desarrollo de las sociedades contemporáneas. Constitucionalmente, se requiere más de una interpretación que concilie la trilogía de la que se habla arriba entre mercados, bienes y derechos. Si el modelo de mercado de la educación quiere garantizar condiciones justas de acceso, se hace necesario no un esquema de gratuidad, sino la corrección inmediata de las limitantes generadas por las fallas del mercado, que crean condiciones limitadas de acceso, como manifestación de condiciones de poder. Se trata de optar por un modelo económico de libertades.

Como se ha entendido la educación como un bien semipúblico, que en su efecto esperado en el mercado se comporta como una externalidad positiva, puede aprovecharse esta condición para definir el marco de intervención limitada, pero relevante, que debe asumir el Estado, mediante acciones concretas que busquen subsidiar, no el mercado, sino, como se ha venido diciendo, el acceso a él. Respecto a las reglas de distribución de la renta y los recursos, el argumento de John Rawls se hace definitivo para entender la lógica de los

\footnotetext{
7 Amartya K. Sen, Desarrollo y libertad, 162 y capítulo 8: La agencia de las mujeres y el cambio social, 233-249, Planeta, Bogotá (2000).

8 Rodolfo Arango-Rivadeneira, El concepto de los derechos sociales fundamentales, 8, Legis, Bogotá (2005).

9 AndRÉs OpPenheImer, ¡Basta de historias! La obsesión latinoamericana con el pasado y las 12 claves del futuro, 114, Random House Mondadori, Debate, Barcelona (2010).
} 
mercados contemporáneos, sobre todo desde su misión de actuar como correctores de inequidades dentro de la economía social.

Es claro que la justicia de las porciones distributivas depende de las instituciones básicas y de cómo asignen la renta total, los salarios y otros ingresos más transferencias. (...) una vez que se obtiene un mínimo adecuado mediante transferencias, puede ser perfectamente justo que el resto de la renta total se determine por el sistema de precios, suponiendo que sea moderadamente eficaz y libre de restricciones monopólicas, y que se hayan eliminado las externalidades irracionales. Además, este modo de tratar las demandas de necesidad puede parecer más eficaz que tratar de regular la renta mediante niveles salariales mínimos. Es mejor asignar a cada rama solo aquellas tareas que sean compatibles unas con otras. Como el mercado no es apropiado para responder a las demandas de la necesidad, estas deben resolverse mediante otra disposición. Que los principios de justicia sean satisfechos depende de que la renta total de los menos aventajados (salarios más transferencias) sea tal que maximice sus expectativas a largo plazo ${ }^{10}$.

Lo que Rawls entiende por transferencias, aquí se puede entender como subsidios que tienen como función alcanzar a cubrir el remanente que no permite el acceso suficiente al mercado educativo en lo que la externalidad positiva entiende como el cubrimiento de la demanda ideal esperada pero no lograda. En este sentido, reiteramos que no necesariamente se trata de un problema de oferta, pues de ahí parte el problema de la externalidad positiva que se asemeja a la naturaleza del bien público, sino de falta de oportunidades de acceso a la oferta existente por falta de capacidades, que es el aporte de Sen, al definir la educación como un bien semipúblico. Un modelo de no gratuidad en la educación se garantiza cuando se hace la conexión del mercado con el derecho. Los derechos pueden coexistir desde la óptica de los mercados y retroalimentarse unos con otros, tan solo que esto requiere ciertas condiciones que obligan a que el Estado y las sociedades tomen parte en el proceso. Entendemos por esto, las acciones concretas que el derecho constitucional define y que buscan intervenir en escenarios sociales y económicos para equilibrar situaciones dispares y desbalanceadas, sobre grupos poblacionales en condiciones de vulnerabilidad, segregación o aislamiento. Sobre todo, para el caso de las acciones afirmativas, se trata de grupos económicos, como las mujeres, los

10 John Rawls, Teoría de la justicia, 259, Fondo de Cultura Económica, FCE, México (2010). 
adultos mayores, las personas discapacitadas y los niños, que no cuentan con el empoderamiento económico ${ }^{11}$, para hacer efectivas sus libertades o, más precisamente, se trata de grupos humanos, discriminados y relegados, que no son libres porque no tienen, ni han tenido por mucho tiempo, acceso a procesos de inclusión en los procesos económicos.

La falta de las posibilidades de acceso a los mercados - esto es, la ausencia de acciones afirmativas concretas - es el punto de partida para crear oportunidades que permitan el ejercicio de los derechos. En concreto, creemos que la falta de acceso a los mercados se presenta por la falta de acceso al proceso educativo, entendido como un mercado que incidirá en el acceso posterior a otros. Si no se tiene acceso a mercados que permiten atender las necesidades básicas, las posibilidades de supervivencia se reducen.

Las economías globales que han alcanzado niveles óptimos de desarrollo no parten de condiciones de fortalecimiento de la economía, sino de fortalecimiento de las políticas administrativas y herramientas judiciales para la protección de los derechos. Generalmente, cuando a las mujeres y niños se les concede la posibilidad de contar con instrumentos para proteger sus derechos, la protección de sus proyectos de vida se hace más efectiva, por lo que se garantiza su sostenibilidad y el aumento, tanto de su expectativa de vida como del grupo de personas, entiéndase menores de edad o personas en condición de discapacidad, que están bajo su responsabilidad, sobre todo, en el caso de las mujeres.

Una manera de responder mediante acciones concretas para empoderar a la mujer son las acciones afirmativas. La economía, por medio del derecho, ha recurrido a instrumentos de regulación jurídica como la intervención en los mercados para otorgar herramientas de empoderamiento económico a la mujer (lo que Rawls llama transferencias), como los programas de apoyo con créditos de consumo o vivienda ${ }^{12}$. La gráfica 1 muestra la situación de países

11 En términos precisos, Sen define el empoderamiento económico como la facilidad para que una persona pueda hacer oponibles sus libertades y optar por un proyecto de vida ajeno a todo tipo de condicionamientos que reduzcan sus posibilidades para decidir. Estas limitaciones pueden venir de falta de políticas en asistencia en salud, cubrimiento en educación, oferta de vivienda o falta de suministros de alimentos básicos, entre otras necesidades. AmArTYA K. Sen, Desarrollo y libertad, capítulo 1: La perspectiva de la libertad, 35, Planeta, Bogotá (2000).

12 Un caso mundialmente reconocido por su éxito como reductor de desigualdades es el Grameen Bank, destinado a la financiación de grupos poblacionales, por medio de microcréditos. BER- 
con políticas de protección a la mujer y una proyección incluyente, lo que resulta en bajos niveles de inasistencia escolar o deserción. Se trata de sociedades que promueven la inclusión; por tanto, las diferencias de género, al comparar niñas y niños, son menores. Por lo general, los altos niveles de discriminación de género en educación subyacen en países con niveles óptimos de crecimiento pero que no necesariamente se reflejan en políticas de inversión para superar las diferencias y condiciones de discriminación en razón del sexo. Las políticas incluyentes, para el asistencialismo de niñas que van a la escuela, demostraron ser efectivas para garantizar su inclusión en los procesos de participación, lo que resulta en menor discriminación sexual.

\section{Gráfica 1}

Niñas que no asisten a la escuela. Nivel primario 2011

\section{Fuente: Banco Mundial, http://www.bancomundial.org/}

Al respecto, en Colombia, el diseño de acciones afirmativas para la inclusión social y la erradicación de la discriminación no han provenido del poder ejecutivo, sino del judicial. La Corte Constitucional ha sido la abanderada en el diseño y adopción de políticas de subsidio para garantizar el acceso a los mercados, en pro de mujeres y niños. Su papel para la reivindicación en derechos sociales fundamentales ha sido ampliamente conocido y el papel que han jugado acciones encaminadas a apoyar necesidades de acceso a la educación se ha vuelto definitivo para alcanzar lo que Amartya Sen denomina el empoderamiento de derechos que garantizan condiciones de desarrollo en una sociedad. Aquí el punto que se discutía arriba, respecto a la suficiencia en los niveles de oferta vuelve a aparecer. El problema no es la reducida disponibilidad del recurso, sino las limitaciones de acceso a él.

Se trata de garantizar el empoderamiento de la persona, en el caso de mujeres, niños y grupos desprotegidos históricamente, mediante la reivindicación del derecho social a la educación mediante el reconocimiento posicional que les había venido siendo negado por

nardo Kliksberg, América Latina. El caso de la salud pública, en Primero la gente, 121-186, 169, Amartya Sen \& Bernardo Kliksberg, Deusto, Barcelona (2007). 
políticas económicas ortodoxas y regresivas. La acción afirmativa reconoce el contenido prestacional del derecho y va alineada en el sentido de garantizar la intervención estatal por medio del gasto público, para romper las barreras que resultan de las fallas del mercado $^{13}$. Lo que aparecía como el reto que proponía la realidad económica, obtuvo su respuesta desde la argumentación en derechos constitucionales que requieren la posición activa del Estado ${ }^{14}$.

La intervención del Estado confirma la condición de derecho prestacional que complementa la naturaleza del derecho social fundamental a la educación, como una herramienta constitucional para corregir inequidades, compensar situaciones desfavorables y eliminar la discriminación. Esta es la prioridad de la educación como medio para la realización de otros derechos.

Aquí se expresa el concepto bien desarrollado de derecho subjetivo como un límite absoluto a los argumentos agregativos: puesto que la negación injustificada del mínimo social es irreconciliable con el estado constitucional y democrático moderno, la justicia compensatoria toma primacía sobre la justicia distributiva, de modo que un análisis de los costos y beneficios de los derechos no puede considerarse. Esto significa que los jueces deben reconocer los derechos sociales fundamentales mínimos por vía de la aplicación de criterios de justicia compensatoria ${ }^{15}$.

Por lo general, los proyectos económicos conservadores se orientan a metas de crecimiento que no incluyen acciones para reducir las condiciones de pobreza, pero sobre todo, el aislamiento en el que viven ciertos grupos poblacionales. La Corte Constitucional ha entrado a reivindicar el derecho a la educación en pro de la estabilización de grupos o personas que han visto reducidas sus posibilidades de acceso a proyectos de educación. Algunos de estos casos se refieren a la definición del derecho social fundamental a

13 Andrés OpPenheimer, ¡Basta de historias! La obsesión latinoamericana con el pasado y las 12 claves del futuro, 155, Random House Mondadori, Debate, Barcelona (2010).

14 El caso típico de acción afirmativa por el derecho de acceso a la educación es el reconocido por la Corte Suprema de Estados Unidos en el fallo Brown v. Board of Education of Topeka, que modificó el precedente existente para garantizar el acceso en condiciones de igualdad a niños negros. Rodolfo ARANGo-RivadeneIra, El concepto de los derechos sociales fundamentales, 191, Legis, Bogotá (2005). United States Supreme Court, Case of Brown v. Board of Education of Topeka, 47 U.S. 483 (1954), decided May 17, 1954. Disponible en: http://www. law.cornell.edu/supremecourt/text/347/483

15 Rodolfo Arango-Rivadeneira, El concepto de los derechos sociales fundamentales, 345, Legis, Bogotá (2005). 
la educación y su conciliación con la autonomía universitaria ${ }^{16}$; garantía del derecho a la educación de las comunidades indígenas ${ }^{17}$; subsidios para educación de personas discapacitadas ${ }^{18}$; protección del derecho a la educación especial de personas discapacitadas ${ }^{19}$; acceso al sistema educativo para menores de edad con problemas de aprendizaje $^{20}$, y garantía de la educación para la mujer en estado de embarazo $^{21}$. Esto se relaciona con el reconocimiento de subsidios, planes de financiación, etc.

Se trata de un derecho, tal como lo dice el artículo 67 constitucional, que requiere condiciones que entren a romper las barreras del mercado para que pueda garantizarse su cubrimiento de manera efectiva. Es un derecho asistencial que requiere acciones concretas por parte de los agentes que modulan las políticas sociales, para que pueda hacerse efectivo. Esto requiere una coordinación entre los

16 Corte Constitucional, Sentencia T-056/11, 4 de febrero de 2011. Magistrado ponente Jorge Iván Palacio-Palacio. Disponible en: http://www.corteconstitucional.gov.co/relatoria/2011/t-056-11. htm. En este caso, el accionante solicita que le sean protegidos sus derechos a la educación, igualdad, debido proceso, libertad de escoger profesión u oficio y al trabajo, por cuanto considera que el plantel universitario donde venía cursando sus estudios profesionales, no podía exigir un nuevo pénsum para terminar sus estudios de ingeniería ambiental, de acuerdo al programa académico que veía cursando.

17 Corte Constitucional, Sentencia T-899/05, 1 de septiembre de 2005. Magistrado ponente Alfredo Beltrán-Sierra. Disponible en: http://www.corteconstitucional.gov.co/relatoria/2005/T-899-05.htm. La acción de tutela tenía como propósito garantizar la etnoeducación de una comunidad de niños indígenas en el departamento del Putumayo, pertenecientes al cabildo indígena Inga de Colón, con educación bilingüe e indígena (inga-castellano) que asegurara la enseñanza de sus propias tradiciones culturales.

18 Corte Constitucional, Sentencia C-559/01, 31 de mayo de 2001. Magistrado ponente Jaime Araújo-Rentería. Disponible en: http://corteconstitucional.gov.co/relatoria/2001/C-559-01. htm. Demanda contra la Ley 21 de 1982, por la cual se modifica el régimen del subsidio familiar.

19 Corte Constitucional, Sentencia T-1015/05, 6 de octubre de 2005. Magistrado ponente Marco Gerardo Monroy-Cabra. Disponible en: http://www.corteconstitucional.gov.co/ relatoria/2005/T-1015-05.htm. El caso se originó en la acción de tutela presentada por la madre de una menor, con el propósito de que le sea reconocido el subsidio educativo para los funcionarios con hijos discapacitados o con capacidades y talentos especiales, toda vez que su hija menor sufre de Síndrome de Turner. En el mismo sentido, cfr. Corte Constitucional, Sentencia T-886/06, 26 de octubre de 2006. Magistrado ponente Marco Gerardo Monroy-Cabra. Disponible en: http://www.corteconstitucional.gov.co/relatoria/2006/T-886-06.htm y Corte Constitucional, Sentencia T-139/13, 14 de marzo de 2013. Magistrado ponente Luis Ernesto Vargas-Silva. Disponible en: http://www.corteconstitucional.gov.co/relatoria/2013/t-139-13. htm

20 Corte Constitucional, Sentencia T-329/97, 11 de julio de 1997. Magistrado ponente Fabio Morón-Díaz. Disponible en: http://www.corteconstitucional.gov.co/relatoria/1997/T-329-97. htm. Para el caso, la madre de un menor solicita la inclusión de su hijo con problemas de aprendizaje en una institución educativa que no le permite hacerlo.

21 Corte Constitucional, Sentencia T-683/02, 22 de agosto de 2002. Magistrado ponente Marco Gerardo Monroy-Cabra. Disponible en: http://www.corteconstitucional.gov.co/relatoria/2002/T-683-02.htm. Una menor interpuso acción de tutela contra la institución educativa donde venía cursando sus estudios, por cuanto fue expulsada en razón a su estado de embarazo. 
diseñadores de las políticas y de los mismos mercados. Su condición de fundamentalidad se debe a la importancia que este guarda para el acceso de otros bienes esenciales en el desarrollo de un proyecto de vida completo. Es un bien fundamental, que hace parte de los mercados y que se ve afectado por sus limitaciones. La educación, como lo indican los casos jurisprudenciales, se convierte en una fuerte herramienta que abre las condiciones para que una sociedad se vuelva desarrollada.

Aquí, la Corte Constitucional ha garantizado la lógica que prevé la Constitución respecto a la dualidad entre derecho a la educación y servicio público esencial. De esta manera, la Corte ha venido respetando las reglas del mercado a la educación, advirtiendo que no se trata de un servicio que debe prestarse de forma gratuita, sino de un derecho que requiere el asistencialismo continuo por parte del Estado. Esto comprende una responsabilidad, tanto de las entidades territoriales como de las autoridades nacionales. Se trata de un servicio que se regula en el nivel nacional pero que requiere la desconcentración $\mathrm{y}$ delegación de funciones territoriales ${ }^{22}$. La carga social y económica que representa esto para el Estado implica adoptar un modelo económico, diferente a los modelos de crecimiento, en el que garantizar condiciones de acceso a los mercados es definitivo para hablar de condiciones de progreso. Desde esta perspectiva, la noción de bien

22 La aspiración de la Constitución es presentar a la educación como una variable que permita la superación de los pueblos, un mecanismo que garantice la convivencia pacífica y se preste de manera eficiente, tanto por particulares como por el sector público, tanto en condiciones de competencia como en condiciones de igualdad. La condición que lo convierte en un servicio público, como lo identifica el artículo 67, lleva a entenderlo como un bien al que se accede por intermedio del mercado. Esto obliga a descartar, en un primer plano, que se trate de un derecho fundamental. Los derechos fundamentales no son bienes sociales para los que se deba acceder a los mercados para adquirirlos. Su condición de bienes jurídicos indeterminados de alto grado de importancia, oponibles al Estado, tal como los identifica Ronald Dworkin, permite concluir que los derechos fundamentales no son negociables ni transables. RONALD DWORKIN, El imperio de la justicia, Gedisa, Barcelona (1988). Creemos que es más afortunado entender la educación como un derecho que se ofrece en los mercados pero que obliga a replantear la naturaleza sobre el tipo de bien del que se trata e, incluso, de la naturaleza del mercado como simple institución que garantiza maximización de intereses. No son bienes que responden necesariamente a los incentivos del mercado, porque algunas realidades demuestran que puede haber limitaciones en la oferta o en la curva de la demanda (Cf. Corte Constitucional, Sentencia C-150/03, 25 de febrero de 2003. Magistrado ponente Manuel José Cepeda-Espinosa. Disponible en: http://www.corteconstitucional.gov.co/relatoria/2003/c-150-03.htm). Es decir, no es un bien que funciona en el raciocinio o bajo los incentivos de los mercados normales. Incluso, el hecho que la Constitución lo reconozca como un derecho fundamental (artículo 44) no garantiza la efectividad del derecho por sí mismo. Constitución Política, 4 de julio de 1991. Disponible en: http://www.alcaldiabogota.gov.co/sisjur/normas/Norma1.jsp?i=4125 
semipúblico guarda cercana relación con la atención de necesidades básicas insatisfechas y derechos. Un modelo económico que no hable de la prevalencia de los derechos es un modelo económico que debe ser descartado. Esto diferencia un modelo eficiente de desarrollo de un modelo eficiente de crecimiento.

Los índices de pobreza ahora no se miden por los niveles de renta, sino por la posibilidad de destinar esa renta a la apropiación de derechos. Es posible que personas con altos niveles de renta no tengan condiciones óptimas para acceder a programas de educación en ninguno de sus niveles ${ }^{23}$, lo que no significa que sean ni las convierte en personas pobres, desde el punto de vista de la renta. Se trata, más bien, de una pobreza en el sentido de las libertades de elegir un proyecto de vida. Es el Estado el que debe atender los casos en que los mercados fallan. No porque se trate de bienes públicos, por cuanto coincidimos con la visión de Sen al hablar de bienes semipúblicos, sino porque se trata de bienes necesarios para la adopción de proyectos de vida elementales.

Arriba se partía de que la educación no es un bien público que deba ser suministrado por el Estado de forma gratuita, pero sí corresponde a este diseñar la política que defina las condiciones en que se garantizan condiciones suficientes de oferta del bien, a la par, con condiciones óptimas para que la demanda alcance esos nichos de oferta. Un ejemplo concreto de este caso es el que se había planteado desde la perspectiva de las acciones afirmativas para las mujeres y las madres cabeza de familia, así como los menores de edad que hacen parte de su núcleo familiar. Lo que queda del análisis que se propone en las siguientes líneas, sugerirá que el reconocimiento y garantía de la asequibilidad (disponibilidad), accesibilidad (acceso), adaptabilidad (permanencia) y aceptabilidad (calidad) de la educación ${ }^{24}$, como criterios básicos para garantizar el derecho a la educación de mujeres y niños, se convertirá en una variable definitiva por medio

23 Por condiciones de acceso se puede entender una oferta óptima del derecho. Personas con niveles de renta alta pero que no cuentan con nichos de oferta del servicio ven imposibilitado su acceso, así como personas con condiciones aceptables de renta pueden no encontrar condiciones dignas de acceso, aunque exista la oferta (personas discapacitadas que no cuentan con accesos dignos a los centros de educación).

24 Carlos Alberto Lerma-Carreño, El derecho a la educación en Colombia, 36, Foro Latinoamericano de Políticas Educativas, FLAPE, Buenos Aires (2007). Disponible en: http://www. redacademica.edu.co/archivos/redacademica/proyectos/ddhh/autoformacion_ddhh/unidad11/ anexo_11-3_el_derecho_a_la_educacion_en_colombia.pdf 
de la cual se pueden modificar las tasas y los índices de mortalidad en una sociedad. En este punto, regresaremos a la hipótesis que se planteaba al inicio del trabajo, según la cual el derecho a la educación se convierte en una variable definitiva para la corrección de los procesos de crisis económicas y sociales en un Estado.

\section{La política de inversión en educación de mujeres y niños como reducción de los indices de mortalidad e inequidad social}

La falta de acceso a la educación se convierte, por regla general, en una causal directa de discriminación ${ }^{25}$. Esto, en términos simples, puede describirse de la siguiente forma. La educación por sí misma no genera resultados verificables en el aumento de los niveles de desarrollo; lo que sí se garantiza mediante la implantación de proyectos educativos, es abrir la puerta de acceso a diferentes tipos de mercados y ofrecer opciones para la realización personal.

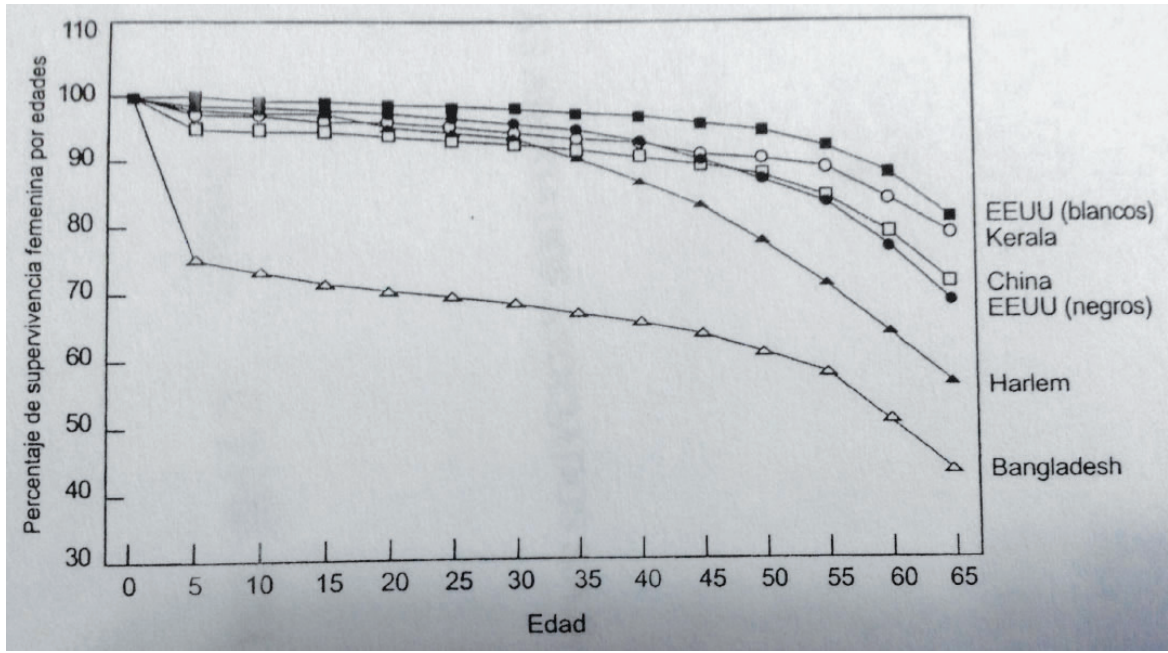

Figura 2

Variaciones en las tasas de supervivencia femenina por sexo y región

Fuente: Amartya Sen, La mortalidad como indicador económico, en Primero la gente, 79-120, 102, Amartya Sen \& Bernardo Kliksberg, Deusto, Barcelona (2007).

25 Amartya K. Sen, Desarrollo y libertad, capítulo 8: La agencia de las mujeres y el cambio social, 233-249, 239, Planeta, Bogotá (2000). 
La figura 2 muestra los niveles de supervivencia de la mujer, teniendo en cuenta país, grupo cultural o región en que habita. Aquí es definitivo el hecho de que incluso en un país como Estados Unidos o India, las condiciones de exclusión y falta de oportunidades pueden variar. La concentración de focos de exclusión se debe a factores culturales, sexuales, raciales y religiosos, que habrán de intensificar las condiciones de pobreza y reducir las oportunidades de progreso, en especial de grupos vulnerables, para el caso, la mujer.

Figura 3

Mortalidad de mujeres en estado de embarazo, 2008

Fuente: Banco Mundial, http://datos.bancomundial.org/noticias/mas-del-99-porciento-de-lasmuertes-maternas-ocurre-en-paises-en-desarrollo

La figura 3 ratifica la tesis anterior. En regiones que se caracterizan por ser centros de exclusión y falta de oportunidades, marcados por ausencia de acceso a mercados o destinación de políticas de asistencia social, la tasa de mortalidad de la mujer es mayor. Regiones donde la pobreza está asentada, como gran parte de América Latina, ciertas zonas de Asia y el sur de África, las probabilidades de que la mujer vea coartada su expectativa de vida y la materialización de un proyecto de vida estable son mayores. Para que el valor adicional que crea la educación en una economía produzca resultados con miras a la reintegración de la gente a la vida social, mediante la creación de oportunidades, es necesario que la misma política educativa se conecte con el resto de la estructura de políticas públicas. Por ejemplo, se puede afirmar que es posible que las aspiraciones de cobertura hacia las cuales se dirige la política en educación se alcancen en un 100\% pero eso no garantizará una mejora en las condiciones económicas de una sociedad. Otra muestra que puede ser indicativa de la inversión de recursos y destinación de políticas públicas, son los niveles de mortalidad y morbilidad de grupos poblacionales reducidos como negros y mujeres. Las figuras 4 y 5 demuestran que la diferencia de oportunidades de sobrevivencia, en comunidades aisladas o apartadas de negros y mujeres, se reduce frente a los grupos dominantes, 
que históricamente han venido siendo protegidos de forma notoria, como los blancos y los hombres.

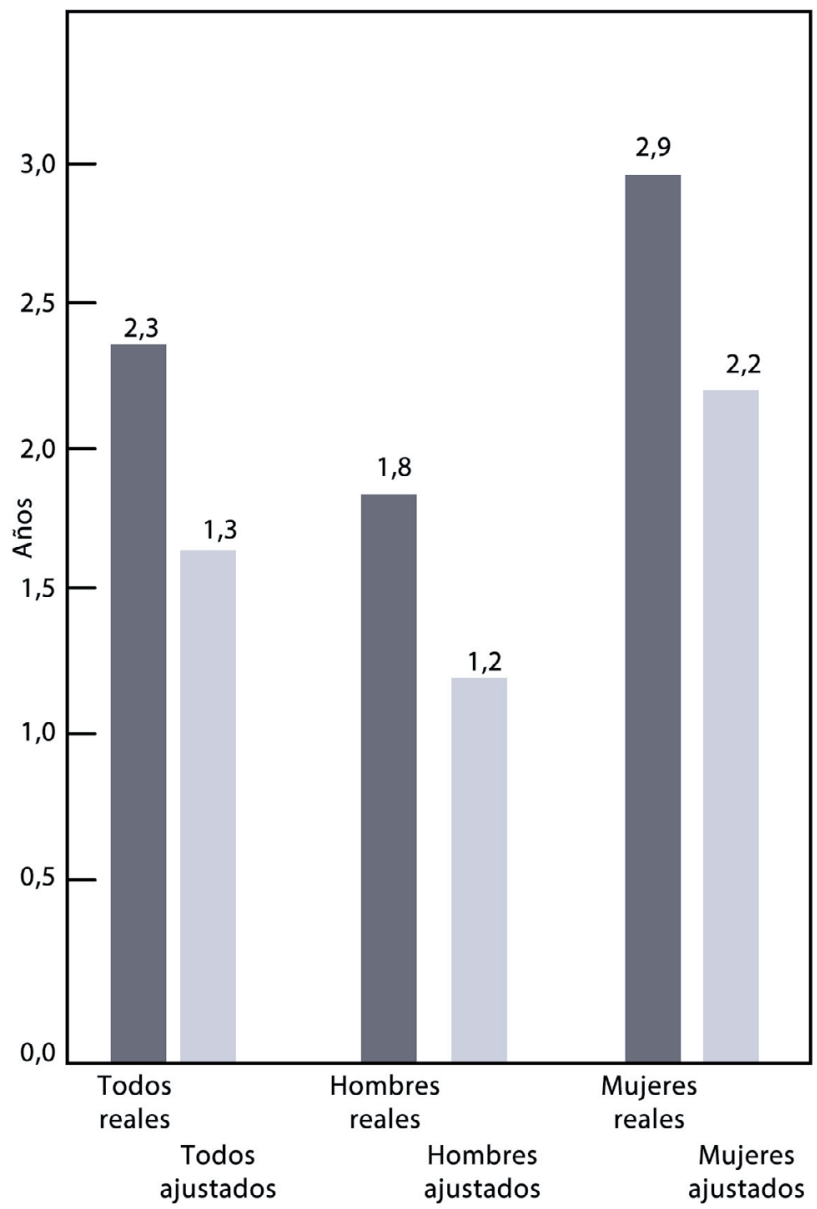

Figura 4

Ratios de mortalidad negros/blancos (35-54 años) reales y ajustados por ingreso familiar

Fuente: Amartya Sen, La mortalidad como indicador económico, en Primero la gente, 79-120, 103, Amartya Sen \& Bernardo Kliksberg, Deusto, Barcelona (2007). 


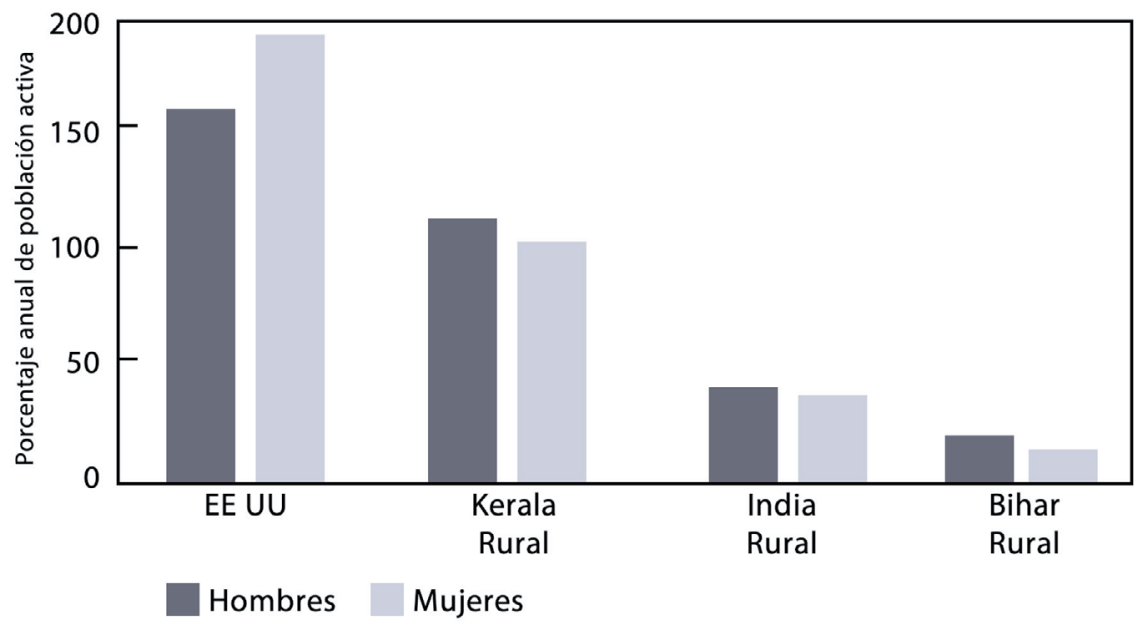

Figura 5

Incidencia de morbilidad reportada: Estados Unidos, Kerala rural, India rural y Bihar rural

Fuente: Amartya Sen, La mortalidad como indicador económico, en Primero la gente, 79-120, 106, Amartya Sen \& Bernardo Kliksberg, Deusto, Barcelona (2007).

En lo que resulta relevante para nuestra hipótesis, cuando a una mujer se le da la oportunidad de verse beneficiada por las políticas educativas, esto repercute directamente en la reducción de las tasas de mortalidad y en las tasas de natalidad, a modo de una política de control demográfico, pero sin necesidad de coerción. No obstante, para que este modelo pueda funcionar requiere una política laboral que permita hacer la conexión entre el valor agregado de la educación y los resultados en desarrollo. Sin esfuerzos para hacer la conexión entre las políticas educativa y laboral, no se podrán obtener los resultados que reflejen la inversión en educación. Menos aún, cuando los recursos que se destinan a atender necesidades educativas, tienden a ser cada vez menores, sobre todo en países como los de América Latina, parte de África y Asia, frente a lo que será la inversión de países en proceso de desarrollo pero con objetivos de políticas de integración constantes en los últimos años, como Israel, Singapur y Costa Rica, como muestran las figuras 6, 7 y 8. 
Figura 6

Gasto público en educación (total \%PIB, 2008)

Fuente: Banco Mundial, http://www.bancomundial.org/

\section{Figura 7}

Mujeres en condición de desempleo $2012(\%)$

Fuente: Banco Mundial, http://www.bancomundial.org/

\section{Figura 8}

Mujeres en condición de desempleo 2012 (\%)

Fuente: Banco Mundial, http://www.bancomundial.org/

Al observar la relación entre las muestras que se recogen en las tres figuras anteriores, los países con menor inversión en educación también hacen parte de los países donde la mujer, sobre todo la que está en condiciones menos favorecidas, no cuenta con garantías suficientes de acceso al mercado de trabajo. Esto incidirá en menores posibilidades en el ejercicio de sus derechos a la sexualidad, derecho a la libre decisión de la maternidad y educación.

\section{Estructura de la política económica en educación a la luz de las reformas constitucionales en materia del sistema de transferencias y sostenibilidad fiscal. Proyecto de reforma económica: 2001-2011}

Habiendo definido las características y el marco de la política en educación, y las características del derecho a la educación, expondremos cómo los proyectos económicos de finales del siglo XX e inicios del XXI han venido retomando los argumentos de la economía conservadora que ha acompañado la historia de Colombia.

Las condiciones de desigualdad social y concentración de riqueza que se hicieron notorias bajo el esquema de la Constitución de $1886^{26}$, trataron de ser reducidas mediante el esquema de descen-

26 Constitución de 1886, 5 de agosto de 1886. Disponible en: http://www.alcaldiabogota.gov.co/ sisjur/normas/Norma1.jsp?i=7153 
tralización territorial que proponía la autogestión administrativa y financiera, en la Constitución de 1991. Para esto, la Ley 60 de $1993^{27}$ definía un esquema de descentralización de la facultad de gasto y la ejecución de recursos para que estos fuesen destinados a la financiación de proyectos educativos. Se trataba de convertir las entidades territoriales en el punto de inicio para el proceso de desarrollo económico y garantía de libertades en el proyecto del Estado Social. Esto es, y era la apuesta de la Ley 60 de 1993: las entidades micro debían dar inicio al proceso de ahorro y depuración presupuestal, descentralización y desconcentración de funciones, para que fuesen esas mismas entidades las que permitieran hacer efectivas las garantías de la población que habita su territorio. De esta manera, se permitirían condiciones de acceso, cobertura y calidad. No obstante, para 2001, hay un cambio de prioridades mediante el Acto Legislativo $01^{28}$ y la Ley 715 de $2001^{29}$ que lo regula. Este conjunto de normas demostrará un proceso de regresión en materia del reconocimiento del derecho a la educación y un incumplimiento de los pactos internacionales en materia de derechos humanos ${ }^{30}$. En la guerra entre las fuerzas del Estado y los grupos armados que se oponen a las estructuras institucionales del modelo constitucional,

27 Ley 60 de 1993, por la cual se dictan normas orgánicas sobre la distribución de competencias de conformidad con los artículos 151 y 288 de la Constitución Política y se distribuyen recursos según los artículos 356 y 357 de la Constitución Política y se dictan otras disposiciones, 12 de agosto de 1993. Disponible en: http://www.alcaldiabogota.gov.co/sisjur/normas/Norma1. jsp?i=274

28 Acto Legislativo 01 de 2001, por medio del cual se modifican algunos artículos de la Constitución Política, 1 de agosto de 2001. Disponible en: http://www.mineducacion.gov.co/1621/ articles-90475_archivo_pdf.pdf

29 Ley 715 de 2001, por la cual se dictan normas orgánicas en materia de recursos y competencias de conformidad con los artículos 151, 288, 356 y 357 (Acto Legislativo 01 de 2001) de la Constitución Política y se dictan otras disposiciones para organizar la prestación de los servicios de educación y salud, entre otros, 21 de diciembre de 2001. Disponible en: http:// www.mineducacion.gov.co/1621/articles-86098_archivo_pdf.pdf

30 La Convención Americana sobre Derechos Humanos, CADH, advierte en su artículo 26 sobre la obligación para los Estados partes de garantizar condiciones progresivas para la protección y atención de derechos. Organización de Estados Americanos, OEA, Convención Americana sobre Derechos Humanos o Pacto de San José, CADH, San José, Costa Rica, 7-22 de noviembre de 1969. Disponible en: http://www.oas.org/dil/esp/tratados_B-32_Convencion_Americana_sobre_Derechos_Humanos.htm. El esquema de las reformas constitucionales sobre transferencias y atención de derechos sociales fundamentales, que se hace visible por el regreso al esquema centralista, reduce el alcance del concepto de desarrollo que trae la Constitución. El proceso de descentralización de funciones, pero sobre todo, de descentralización de las finanzas públicas era la apuesta del constituyente de 1991 para dar paso a la autonomía territorial y a la generación de condiciones de progreso, mediante la cobertura y atención en educación y salud, como sectores prioritarios. Esta era la propuesta que traía la Ley 60 de 1993, derogada por la Ley 715 de 2001. 
el principal derrotado será el derecho a la educación. Se trata del triunfo del modelo de crecimiento económico y política contrainflacionaria que se había iniciado para la década de 1970, como respuesta al aumento del déficit fiscal para financiar las políticas contra el narcotráfico y el endeudamiento público.

\section{Figura 9}

\section{Porcentaje del PIB en gasto militar del gobierno, 2013}

Fuente: Banco Mundial, http://www.bancomundial.org/. El gasto incluye el personal militar y civil.

Esto marcará un contraste con el esquema que plantea la Constitución en el que la educación es un servicio público y un derecho que se garantiza por medio de los mercados, lo que incidirá en la reducción de los niveles óptimos de las condiciones que acompañan el servicio de la educación y que fueron la prioridad de la Corte Constitucional durante los años de definición del núcleo del derecho (1992-2012). El resultado de la centralización de las políticas públicas que se han puesto en marcha durante los últimos diez años, ha reducido la oportunidad y facilidad de las entidades territoriales de garantizar el acceso y cobertura del derecho a la educación. El mercado de la educación requiere inversión, tanto nacional como territorial, para convertirse en un factor de resocialización y equilibrio de desigualdades. Este modelo se verá perfeccionado con el proyecto de modelo económico que propone la reforma constitucional del Acto Legislativo 03 de $2011^{31}$, en el cual el gobierno de Juan Manuel Santos aprueba el principio de sostenibilidad fiscal que representará un retroceso en el activismo judicial de la Corte Constitucional, pero sobre todo, representará hacia el largo plazo, un freno a la rehabilitación de sectores sociales marginados, como los grupos poblacionales excluidos que reconocían las sentencias sobre el estado de cosas inconstitucional que la Corte Constitucional había venido identificando y protegiendo desde $1997^{32}$, en el cual hay una violación sistemática de derechos.

31 Acto Legislativo 03 de 2011, por el cual se establece el principio de la sostenibilidad fiscal, 1 de julio de 2011. Disponible en: http://www.alcaldiabogota.gov.co/sisjur/normas/Norma1. jsp?i=43214

32 Sobre los antecedentes y proyección del estado de cosas inconstitucional, puede consultarse mi texto: Luis Ricardo Gómez-Pinto, El juez de las políticas públicas, Grupo Editorial Ibáñez, 
Los procesos de reformas constitucionales que se desplegaron durante la primera década del siglo XX se orientan a proteger variables de crecimiento económico, como reducción del gasto público, reducción del intervencionismo y el activismo judicial en materia de derechos, lo que ha legitimado el discurso enmarcado en un modelo de economía conservadora. Esto ha permitido darles continuidad a los procesos de reforma, cuando la economía es medida por el resultado en el aumento de las tasas de crecimiento. No obstante, como se insinuaba páginas atrás, el costo social de estos procesos es muy alto, sobre todo en sectores vulnerables, como las mujeres madres cabeza de familia, los niños y los jóvenes. Las políticas de restricción del gasto público social - como la reducción de la descentralización financiera y la destinación de recursos a proyectos y derechos sociales - , como el objetivo de la sostenibilidad fiscal, inciden en la reducción del empoderamiento de la persona sobre sus libertades.

En el caso de las mujeres, por ejemplo, la falta del reconocimiento de libertades tiene una incidencia definitiva sobre los niveles de progreso, medido en función de los índices de supervivencia de la mayoría de los niños menores de cinco años que están a su cargo. La figura 10 muestra con particular atención la esperanza de vida al nacer de las niñas, que, de acuerdo a lo que describe Sen, son las que pueden verse más afectadas por las políticas regresivas en asistencia social, como la inversión pública en educación, salud, alimentación y vivienda en países donde hay políticas de discriminación por género o que, por diversas circunstancias, generan contextos de prejuicio misógino ${ }^{33}$.

\section{Figura 10}

\section{Esperanza de vida al nacer en años, 2012}

Fuente: Banco Mundial, http://www.bancomundial.org/

Cuando los proyectos económicos hablan de la reducción de intervención progresiva en materia de derechos económicos, como

Pontificia Universidad Javeriana, Bogotá (2012).

33 Amartya Sen, La mortalidad como indicador económico, en Primero la gente, 79-120, 97, Амartya Sen \& Bernardo Kliksberg, Deusto, Barcelona (2007). 
la educación, se reducen las condiciones en que las mujeres pueden proteger con mayor seguridad, tanto física como económica, su núcleo familiar.

Capacitar en procesos de enseñanza de escritura y lectura ${ }^{34}$ permite hacer efectivos los derechos que facilitan el desarrollo de proyectos de vida que sin esa capacitación serían casi imposibles de acceder, como la opción de búsqueda de una oferta laboral o la posibilidad de recurrir al mercado bancario en busca de un crédito de consumo o vivienda. Esto es lo que las reformas constitucionales no parecen garantizar. Con estas perspectivas, en la última parte de este punto, se planteará lo siguiente. Veremos cómo las reformas al régimen de transferencias y la modificación del sistema de planeación han desconocido las políticas en inversión social en educación y están dirigiendo la regulación económica hacia la economía de la desigualdad. Más que ser una respuesta a las crisis económicas, las reformas constitucionales que se han ido planteando como mecanismos de regulación de las crisis inflacionarias o de gasto público, se han convertido en la causa para el asentamiento de las brechas de la discriminación. Esto, en un marco de reducción de la autonomía territorial y de la financiación de proyectos de impacto social, que reducen las condiciones de libertad.

\section{A. Reforma al régimen de transferencias}

Las políticas de la Ley 30 de $1992^{35}$ y de la Ley 115 de $1994^{36}$ se amparan en el esquema de descentralización de la inversión y el gasto público social que proponía la Ley 60 de $1993^{37}$, según el

34 Cf. el caso de Corea del Sur. Andrés Oppenheimer, ¡Basta de historias! La obsesión latinoamericana con el pasado y las 12 claves del futuro, 180, Random House Mondadori, Debate, Barcelona (2010).

35 Ley 30 de 1992, por la cual se organiza el servicio público de la Educación Superior, 29 de diciembre de 1992, Disponible en: http://www.secretariasenado.gov.co/senado/basedoc/ ley_0030_1992.html

36 Ley 115 de 1994, por la cual se expide la ley general de educación, 8 de febrero de 1994. Disponible en: http://www.secretariasenado.gov.co/senado/basedoc/ley_0115_1994.html. CARLOS Alberto Lerma-Carreño, El derecho a la educación en Colombia, 16, Foro Latinoamericano de Políticas Educativas, FLAPE, Buenos Aires (2007). Disponible en: http://www.redacademica.edu.co/archivos/redacademica/proyectos/ddhh/autoformacion_ddhh/unidad11/ anexo_11-3_el_derecho_a_la_educacion_en_colombia.pdf

37 Cf. Sentencia C-520/94, entre otras. Corte Constitucional, Sentencia C-520/94, 21 de noviembre de 1994. Magistrado ponente Hernando Herrera-Vergara. Disponible en: http://www. corteconstitucional.gov.co/relatoria/1994/C-520-94.htm 
cual las entidades territoriales tenían una amplia participación y responsabilidad en impulsar proyectos educativos que garantizaran la inclusión social. La institución del situado fiscal era definitiva para alcanzar este propósito ${ }^{38}$. Pese a esto, la visión de la descentralización como variable de desarrollo, fue aislada paulatinamente por los proyectos de política económica del gobierno. Las reformas al régimen de transferencias en 2001 y en 2007 (Actos Legislativos 01 y 04, respectivamente) menguaron el efecto que proponía el esquema de descentralización de la educación en la Constitución. Esto trajo consigo la cancelación del proyecto y la actualización del progresismo educativo que empezó con las Leyes 30 y 60. Desde 1993, Colombia, más que una reforma al modelo educativo, no ha actualizado un esquema de financiación estructural de los sectores vulnerables en materia educativa. Esto es, las regiones y sectores sociales, como mujeres cabeza de familia y menores de edad, se vieron aislados del proyecto de reorganización presupuestal que dio comienzo en 2001.

Los Actos Legislativos 01 de 2001 y 04 de 2007, y con ellos la Ley 715 de 2001, reducen los efectos de la reforma educativa al interrumpir el proceso que se llevaba bajo la Ley 60 de 1993, en el cual la figura progresista del situado fiscal era clave para crear los incentivos suficientes a las entidades territoriales con el fin de adquirir autonomía presupuestal a largo plazo mediante la descentralización de las finanzas públicas. Ahora, se opta por la centralización del reparto de recursos y la concentración del acceso al sector financiero. Así, el impacto de la proyección en educación,

38 El sistema de transferencias se componía de dos partes. El situado fiscal, suspendido por el Acto Legislativo 01 de 2001 y luego eliminado por el Acto Legislativo 04 de 2007, correspondía al porcentaje de ingresos corrientes de la nación que se entregaban a las entidades territoriales para la atención de las necesidades en educación y salud. El objetivo de la Ley 60 de 1993 era reducir paulatinamente el porcentaje de ingresos con el propósito que los departamentos y distritos asumieran las cargas presupuestales en mayor medida. La otra parte del sistema de transferencias correspondía al porcentaje de participaciones que correspondía a los porcentajes de ingresos nacionales que se repartían para libre disposición en los entes territoriales, para complementar los servicios que la misma ley fijaba. Se trataba de una herramienta anexa al situado fiscal que buscaba cubrir la asistencia en materia de necesidades básicas de la población en diversos sectores sociales. Hoy, el Sistema General de Participaciones, bajo la reforma del Acto Legislativo 04 de 2007, define el método para la asignación de recursos, que amplió las fuentes de destinación pero al eliminar el situado fiscal, se redujeron las fuentes de financiación del gasto territorial, lo cual condiciona los proyectos de inversión social. En términos sencillos, se ampliaron los gastos pero se redujeron los ingresos, con lo que se limita, indirectamente, la autonomía de las entidades territoriales. 
como capital humano, y de la política laboral, que sirven para medir los niveles de productividad de un país ${ }^{39}$, se ven reducidos. Los avances en materia de educación, después de casi 14 años de vigencia del Acto Legislativo 01 de 2001 y de la Ley 715 de 2001, no dan muestras de progreso en el sentido de ampliar la cobertura en educación, y tampoco se ve cómo el modelo de crecimiento va a garantizar la autonomía de inversión.

\section{Figura 11}

Gasto por alumno nivel primario (\% PIB per cápita), 2009

Fuente: Banco Mundial, http://www.bancomundial.org/

Los Actos Legislativos 01 de 2001 y 04 de 2007 hicieron propicio el marco constitucional que permitiese garantizar el proyecto de centralización del manejo de los recursos de inversión social, amparado en reducir el despilfarro que venían asumiendo las entidades territoriales por ausencia de autogestión y combate de la variable de corrupción, que no se ve modificada para nada por las reformas. Por otro lado, algunos economistas sostienen que la economía social de mercado, en el discurso de la economía de la integración, hace una advertencia clara al respecto. La descentralización de políticas públicas como las de educación y salud, no solo incrementa los niveles de eficiencia en la prestación del servicio, y si se quiere, en la ética del mercado, lo que representa una reducción de las cargas presupuestales del sector central, sino que además genera competitividad en la mano de obra de un país, lo que repercute en los niveles de productividad. De ahí que se justifique, como lo señala N. Gregory Mankiw, la inversión y subsidios para el sector educativo ${ }^{40}$. Bernardo Kliksberg lo advierte para el caso de los servicios de salud, que, creemos, no es muy diferente al sector educativo:

Ello requiere transitar caminos como, entre otros, la descentralización de las políticas y servicios de salud. El nivel local permite operar con mayor eficiencia gerencial, dar respuestas más directas, incorporar las reacciones de la población, da más flexibilidad y abre más posibilidades a la participación de la comunidad. Pero demanda fortalecer las capacidades gerenciales locales y

39 N. Gregory Mankiw, Principios de economía, 343, McGraw-Hill, Madrid (2004).

40 N. Gregory Mankiw, Principios de economía, 344, McGraw-Hill, Madrid (2004). 
garantizar que la acción esté orientada hacia la comunidad y no sea captada por intereses partidistas o grupos de presión económicos de la zona.

Una gran vía para potenciar las posibilidades de la descentralización y, a su $v e z$, fuente de generación de valores agregados fundamentales a un proceso efectivo de salud, es el empoderamiento de las comunidades pobres ${ }^{41}$.

Se trata de la visión que en educación hemos venido llamando la apertura de oportunidades para garantizar el ejercicio de capacidades, lo que aquí aparece condicionado a una política de descentralización administrativa y territorial para que las comunidades y sectores puedan encontrar su propia identidad cultural y educativa. Esto se convierte en un valor estrechamente ligado al desarrollo de los sectores poblacionales, de acuerdo a su cultura, creencias y tradiciones pero, sobre todo, realidades. El sentido de pertenencia por la educación y el hecho de sentir un proyecto/mercado educativo como propio, intensifica el valor agregado que crea la educación en una sociedad. Lo anterior se hace material cuando la educación determina la capacitación que abre las puertas a todo proceso de producción laboral. En este sentido, la política económica que incorporan las reformas al sistema de transferencias, al eliminar el situado fiscal, escoge un costo de oportunidad en el sentido de reducir la financiación y sostenimiento del sector educativo, con el propósito de fortalecer la financiación nacional de proyectos.

\section{B. E1 principio de sostenibilidad fiscal}

Como se venía diciendo, las políticas de inversión pueden ser determinantes para la participación del sector privado en educación. Esta lógica parte del supuesto de que las entidades territoriales pueden administrar y gestionar su presupuesto como herramienta macroeconómica territorial. El sistema de transferencias preveía que los recursos se destinaran a necesidades esenciales con el fin de fortalecer el funcionamiento de los mercados y garantizar condiciones de acceso. La idea original en 1991 sostenía que una vez los mercados cubrieran de forma suficiente la atención de servicios públicos esenciales a partir de la visión de la descentralización fi-

41 Bernardo Kliksberg, América Latina. El caso de la salud pública, en Primero la gente, 121-186, 177, Amartya Sen \& Bernardo Kliksberg, Deusto, Barcelona (2007). 
nanciera y territorial, el sector privado encontraría los incentivos suficientes para invertir en estos sectores, como condición de libre mercado, libre competencia y la libertad de ingreso, con una perspectiva social de mercado, en la cual la competencia termina por beneficiar al consumidor.

El efecto de las políticas regresivas en asistencialismo social representa una amenaza a la sostenibilidad de los derechos, lo que fortalece el foco de generación de inequidades. La economía de la desigualdad, que ha venido creando las crisis sociales y económicas, se fortalece con este tipo de medidas. En este panorama, la reforma del Acto Legislativo 03 del 1 de julio de 2011 ${ }^{42}$, que adopta el principio de la sostenibilidad fiscal, ratifica esta postura.

La sostenibilidad fiscal ${ }^{43}$ busca limitar el gasto público de las entidades del Estado, en concreto, el que se pueda generar por decisiones provenientes de la rama judicial. Para esto, por una parte, la reforma está condicionando la inversión que las entidades territoriales puedan hacer en el gasto público social, vía presupuestos, para que sea solo el sector central el que defina la inversión en sectores estratégicos para el desarrollo y que, obviamente, son los que más costos representan para una política presupuestal. Por otra, el condicionamiento final de la reforma constitucional se dirige contra la intervención de las altas cortes en materia de derechos económicos, que son los que requieren constante intervención por el Estado. Las acciones afirmativas de la Corte Constitucional ya demostraron su efectividad para cerrar las brechas de indiferencia social por medio de los derechos sociales fundamentales, pero ahora la intervención judicial que parecía garantizar esos derechos se ve reducida.

Con la reforma del Acto Legislativo 03 de 2011 se está haciendo una modificación tácita de la figura del gasto público social de los artículos 350 y 366 constitucionales, y los avances que la Corte Constitucional había realizado al empoderar el reconocimiento

42 La sostenibilidad fiscal modifica los artículos 334, 339 y 346 de la Constitución. Sin embargo, el núcleo de la reforma está en el artículo 334 de la Constitución, al cual puede remitirse el lector. Acto Legislativo 03 de 2011, por el cual se establece el principio de la sostenibilidad fiscal, 1 de julio de 2011. Disponible en: http://www.alcaldiabogota.gov.co/sisjur/normas/ Norma1.jsp?i=43214

43 Sobre la constitucionalidad del Acto Legislativo, Corte Constitucional, Sentencia C-288/12, 18 de abril de 2012. Magistrado ponente Luis Ernesto Vargas-Silva. Disponible en: http:// www.corteconstitucional.gov.co/relatoria/2012/C-288-12.htm 
de derechos sociales a grupos poblacionales aislados y limitados económicamente, como es el caso de las declaratorias de los estados de cosas inconstitucionales. Se trata, como en el caso de la educación, de derechos que quedaron excluidos de la protección y blindaje judicial que hacía el tribunal constitucional y ahora pasan a depender de las políticas y prioridades del Ejecutivo, cuando es este quien ha venido incidiendo de manera directa en el crecimiento del déficit fiscal. Al respecto, el incidente del impacto fiscal le da la atribución a la rama ejecutiva y a la Procuraduría General para controvertir las decisiones judiciales que puedan representar un desequilibrio fiscal o un desajuste en materia de gasto público, cuando de lo que se trata, de acuerdo a la lógica en que se ampara la restricción de deuda pública, conocida como la regla fiscal, es de restringir niveles de endeudamiento ${ }^{44}$. Cuando se hablaba de la intervención del juez en política económica, se hablaba de un proyecto de progreso. El argumento que garantizaba la intervención judicial era el de la inversión en sectores sociales prioritarios, como educación, salud y servicios públicos, lo que incide directamente en la reducción de las tasas de mortalidad infantil ${ }^{45}$. El argumento de la sostenibilidad fiscal va en otra dirección. El crecimiento económico se olvida de la variable libertad que se había venido garantizando mediante el activismo judicial en materia de protección de derechos prestacionales y que, de manera muy limitada o casi inexistente, como lo demuestran estudios sobre el tema, ese activismo estaba alterando las previsiones de la Ley del Presupuesto General destinadas al gasto público ${ }^{46}$. La reorientación de las destinaciones en

44 Al respecto, debe tenerse presente que la regla fiscal (Ley 1473 de 2011, por medio de la cual se establece una regla fiscal y se dictan otras disposiciones, 5 de julio de 2011. Disponible en: http://www.alcaldiabogota.gov.co/sisjur/normas/Norma1.jsp?i=43236) guarda una finalidad muy diferente a lo que busca el Acto Legislativo 03 de 2011. La primera imparte condiciones y topes de endeudamiento al gobierno con el fin de reducir los niveles de déficit en el mediano y largo plazo. Esto va de la mano con las reformas internacionales que se han ido adoptando para frenar el acelerado proceso de déficit de los gobiernos que venían desfinanciando sectores de inversión social en países como Italia, Alemania, Grecia y España. Mientras que la sostenibilidad fiscal busca disminuir el poder de intervención de las Cortes en materia de gasto e inversión social.

45 Bernardo Kliksberg, América Latina. El caso de la salud pública, en Primero la gente, 121-186, 171, Amartya Sen \& Bernardo Kliksberg, Deusto, Barcelona (2007).

46 Helena Alviar-García, Uso y limites de la acción pública de inconstitucionalidad en Colombia, en Teoría constitucional y politicas públicas, bases críticas para una discusión, 477-519, MANUEL José Cepeda, Eduardo Montealegre-Lynett \& Alexei Julio-Estrada, coords., Externado de Colombia, Bogotá (2007). 
materia presupuestal es mínima frente al beneficio social que representaba el reconocimiento y protección de derechos sociales que las Cortes han venido haciendo, sobre todo en materia de acción de tutela y acción pública de inconstitucionalidad, como se pudo constatar al hablar de las acciones en educación.

En esta medida, el Acto Legislativo 03 de 2011 es la respuesta del gobierno al activismo de la Corte Constitucional en materia de derechos sociales. No obstante, el intervencionismo de la Corte mediante sentencias de constitucionalidad en materia de Hacienda Pública era mínimo; además, se demuestra que en materia de rentas y normatividad tributaria las restricciones que ha impuesto la Corte son casi del $0 \%{ }^{47}$. Para hablar de un crecimiento económico sostenido, como es el objetivo de la sostenibilidad fiscal, se debe hablar primero de la inversión en sectores que garanticen la libertad de acceso a bienes (semipúblicos) como la educación, no de desprotección de derechos sociales. El Acto Legislativo 03 de 2011 termina por cerrar el círculo en relación con el proyecto centralizador de gasto público y la reducción de la descentralización que habían iniciado las reformas de los Actos Legislativos 01 de 2001 y 04 de 2007, ahora mediante el condicionamiento del intervencionismo que venían haciendo las Cortes en materia de derechos sociales. Se trata de reducir el impacto que generaba el control judicial como variable macroeconómica, en lo que se refiere al gasto social que se originaba en el incentivo a la promoción del capital humano, lo que se esperaría generara una mejora en las condiciones de productividad de un país, mediante la relación entre el mercado laboral y el mercado educativo.

Así pues, el principio de la sostenibilidad tiene un propósito que se enmarca dentro de una tendencia netamente liberal, en el sentido de propiciar el reduccionismo estatal, como lo habían promulgado los modelos de economía conservadora de mediados y finales del siglo $\mathrm{XX}$, que dieron prioridad a proyectos de centralismo como variable de crecimiento. Sin embargo, el costo de este reduccionismo, dado el contexto de crisis de acceso a derechos que advertía

47 Helena Alviar-García, Uso y límites de la acción pública de inconstitucionalidad en Colombia, en Teoría constitucional y políticas públicas, bases críticas para una discusión, 477-519, 504-505, Manuel José Cepeda, Eduardo Montealegre-Lynett \& Alexei Julio-Estrada, coords., Externado de Colombia, Bogotá (2007). 
la Corte Constitucional, pero sobre todo, de limitación en la articulación de la política educativa de mujeres y niños, con miras a alcanzar una política laboral que haga sostenible un equilibrio equitativo entre oferentes y demandantes de trabajo, repercute en la desprotección a largo plazo de sectores menos favorecidos, como los grupos de mujeres cabeza de familia y los niños. Una política educativa que sirva de cultivo al capital humano y que apalanque el acceso al mercado laboral se hace ilusoria, lo que - para Sen y los proyectos de desarrollo de derechos - representa un costo social demasiado alto.

Para garantizar condiciones óptimas de crecimiento, se deben garantizar primero condiciones dignas de desarrollo. El argumento de los bienes semipúblicos como condición de desarrollo habla de la carga del Estado por internalizar las crisis de los mercados y el derecho, mediante la apertura al desarrollo, al garantizar condiciones óptimas de educación básica que cierran las brechas de indiferencia y segregación económica ${ }^{48}$.

\section{La integración de las políticas como garantía para el desarrollo. La política laboral en Colombia como medición del valor agregado en educación}

Las más recientes reformas estructurales que se han adelantado en materia labora ${ }^{49}$ y en restricción del gasto público social incorporadas mediante la reforma al Sistema General de Participaciones y la incorporación del principio de sostenibilidad fiscal, han terminado por reducir los efectos que el proyecto de descentralización de la Constitución de 1991 proponía para el acceso a libertades y garantías de inclusión social. Esto se refleja en el hecho de que la reducción del gasto público y su orientación hacia sectores vulnerables, reduce las oportunidades de acceso a bienes esenciales que permitan garantizar el pleno goce de los derechos. Colombia

48 Amartya K. Sen, Desarrollo y libertad, capítulo 5: Mercados, Estado y oportunidad social, 142-182, 163, Planeta, Bogotá (2000).

49 Ley 789 de 2002, por la cual se dictan normas para apoyar el empleo y ampliar la protección social y se modifican algunos artículos del Código Sustantivo de Trabajo, 27 de diciembre de 2002. Disponible en http://www.alcaldiabogota.gov.co/sisjur/normas/Norma1.jsp?i=6778. Ley 1429 de 2010, por la cual se expide la Ley de Formalización y Generación de Empleo, 29 de diciembre de 2010. Disponible en: http://www.alcaldiabogota.gov.co/sisjur/normas/Norma1. jsp?i $=41060$ 
muestra un esquema educativo limitado que no responde a las crisis sociales y económicas que afronta el país, lo que lleva a hablar de un esquema regresivo de inversión y gasto en educación. En este sentido, las reformas que buscan ajustar las variables económicas como la política inflacionaria, la política fiscal y la política de endeudamiento del Estado, se han convertido en la causa de las crisis modernas de los derechos humanos. La priorización de políticas de restricción del gasto social ha reorientado las prioridades y los discursos constitucionales, cuando en materia de resultados económicos comparados, todo parece indicar lo contrario cuando de garantizar el crecimiento económico se trata. El tema de las políticas de inversión en educación, su relación con las medidas coercitivas para el control de la natalidad y el asistencialismo en materia de servicios esenciales, parece reenfocar el debate en política económica.

Es razonable aceptar que muchos de los antiguos programas sociales y económicos de China han conseguido reducir la fecundidad, incluidos los que han expandido la educación (de las mujeres y de los hombres), han facilitado más el acceso a la asistencia sanitaria, han brindado más oportunidades de empleo a las mujeres y (...) han estimulado el crecimiento económico. Es posible que estos factores hayan tendido a contribuir a reducir la tasa de natalidad, y no se sabe cuánto más ha conseguido reducir China las tasas de fecundidad con la política coercitiva. De hecho, incluso en ausencia de coacción, sería de esperar que la tasa de fecundidad de China fuera mucho menor que la media india, dado que China ha obtenido unos resultados mucho mejores en el campo de la educación, la asistencia sanitaria, las oportunidades de empleo de las mujeres $y$ otros ingredientes del desarrollo social ${ }^{50}$.

En Colombia, las recientes reformas en materia laboral han reducido los efectos positivos que habían creado las reformas educativas y de finanzas públicas que se amparaban en el proyecto de descentralización territorial, mediante transferencias como variable de desarrollo. Al disminuir la inversión en proyectos educativos, se reducen los incentivos para la creación y el acceso a los espacios de trabajo, lo que congela la expansión en productividad y los resultados en el mercado laboral. Parece que este tipo de medidas, no solo

50 Amartya K. Sen, Desarrollo y libertad, capítulo 9: Población, alimentos y libertad, 250-275, 268-269, Planeta, Bogotá (2000). 
en Colombia, sino en la mayoría de los países de Latinoamérica ${ }^{51}$, se vuelve una constante para generar brechas de inequidad, pero sobre todo focos de concentración de riqueza. La política económica que han adelantado los gobiernos que optan por la prevalencia del sistema de mercados, dirige sus esfuerzos presupuestales hacia la priorización de políticas ortodoxas de centralización de recursos, esto, como lo advertía Eduardo Galeano, para el ajuste de la regulación normativa interna con el propósito de definir políticas que hablan de la reducción del intervencionismo en economía social pero que sobre todo pueda facilitar los proyectos armamentistas de la región. La Ley 789 de 2002 y la Ley 1429 de 2011, encaminadas a la flexibilización laboral y la reducción de las cargas económicas para las empresas, son una muestra de esto. Las leyes parecen haber creado condiciones para incentivar la creación de empleo en pequeña escala para los grandes sectores económicos, pero no haber creado los suficientes incentivos para la creación y financiación de la micro y pequeña empresa en los sectores con menor capacidad de acceso a los mercados competitivos hacia el largo plazo $^{52}$, y en los cuales los profesionales que terminan sus procesos de educación tienden a ingresar directamente. Se trata de normatividades que parten de una lógica de crecimiento económico como condición para el desarrollo ${ }^{53}$.

Con esto se reducen las condiciones para creación de oportunidades y los incentivos para optar por un proyecto educativo. Se trata de leyes efectivas para los sectores empresariales, pero que no hablan de una política laboral articulada con una política de regulación de mercados educativos. Formular políticas de educación encaminadas a cerrar la brecha de indiferencia y discriminación sobre la mujer, permite recoger el valor adicional que crea la educación para los mercados y las sociedades. Esta capacitación, desde niña, permite a la mujer no solo desempeñar un rol en el mercado laboral, sino que además le brinda la posibilidad de decidir, de

51 AndRÉs OpPenheImer, ¡Basta de historias! La obsesión latinoamericana con el pasado y las 12 claves del futuro, Random House Mondadori, Debate, Barcelona (2010).

52 Bernardo Kliksberg, América Latina. El caso de la salud pública, en Primero la gente, 121-186, 133, Amartya Sen \& Bernardo Kliksberg, Deusto, Barcelona (2007).

53 Édgar Novoa-Torres, Reestructuración, campos jurídicos y Corte Constitucional, en Intelectuales, tecnócratas y reformas neoliberales en América Latina, 347-382, 374, JAIro EsTRADA-ÁLvareZ, ed., Universidad Nacional de Colombia, Convenio Andrés Bello \& Colciencias, Bogotá (2005), en adelante, Intelectuales. 
mutuo acuerdo con el hombre o sola ${ }^{54}$, por la orientación, inversión y decisión de los gastos en el núcleo familiar. Aquí se puede medir la relación entre la formación del capital humano y su incidencia en los niveles de crecimiento de un país. La mujer gana en participación mediante la materialización de su libertad. Al ganar libertad, la mujer y los niños ganan empoderamiento para decidir y ser parte del proyecto de progreso. Esto les permite convertirse en un factor cuantificable de desarrollo pues está incidiendo sobre los niveles de natalidad de su grupo familiar, en razón de su capacidad y autonomía económica. La relación entre el valor agregado que aparecía como indefinido de la educación y los mercados laborales se hace identificable para poder hablar de condiciones de progreso.

Aunque las mujeres trabajan muchas horas al dia en el hogar, como este trabajo no está remunerado, no suele tenerse en cuenta cuando se contabilizan las respectivas aportaciones de las mujeres y de los hombres a la prosperidad conjunta de la familia. Sin embargo, cuando la mujer trabaja fuera de la familia es más viable. También tiene más voz, ya que depende menos de otros. Parece que la mejora de la posición de las mujeres afecta incluso a las ideas sobre los deberes de las hijas. Por lo tanto, la libertad para buscar y tener trabajo fuera del hogar puede contribuir a reducir las privaciones relativas - y absolutas - de las mujeres. Parece que la libertad en un área (la de poder trabajar fuera del hogar) contribuye a fomentar la libertad en otras (la libertad para no pasar hambre, no padecer enfermedades y no sufrir privaciones relativas $)^{55}$.

Ahora, la mujer tiene la posibilidad de recibir un ingreso de acuerdo a su actividad laboral, lo que le permitirá hacer viable su proyecto de libertad. Aquí, los economistas coinciden al señalar $-\mathrm{y}$ es lo que debe valorarse en un proyecto económico- que la relación

54 Sobre el caso de las mujeres cabeza de familia, MCF, la Corte Constitucional las definió como sujetos de especial protección. La MCF se refiere a la mujer que asume la responsabilidad exclusiva de su núcleo familiar. De acuerdo a la sentencia SU-388/05, la mujer cabeza de familia es aquella que tiene bajo su responsabilidad a menores de edad, personas en condición de incapacidad física o en estado de incapacidad moral. Corte Constitucional, Sentencia SU388/05, 13 de abril de 2005. Magistrado ponente Clara Inés Vargas-Hernández. Disponible en: http://www.corteconstitucional.gov.co/relatoria/2005/SU388-05.htm. Los hechos del caso mencionado son los siguientes: con base en la Ley 790 de 2002, el Estado adelantó el proceso de reforma de la rama ejecutiva, lo que conllevó la liquidación, supresión o fusión de varias entidades del Estado. Varias mujeres cabeza de familia, funcionarias de la empresa de telecomunicaciones Telecom, presentaron acciones de tutela solicitando el reintegro a la empresa, por cuanto consideraron que vieron vulnerados sus derechos fundamentales como mujeres cabeza de familia, al igual que los de las personas que estaban a su cargo.

55 Amartya K. Sen, Desarrollo y libertad, capítulo 8: La agencia de las mujeres y el cambio social, 233-249, 239, Planeta, Bogotá (2000). 
entre los años de capacitación y el nivel de ingreso es directamente proporcional $^{56}$. Esa libertad se puede medir, no solo en función del ingreso, sino en la posibilidad de decidir la destinación de su tiempo en su núcleo familiar. Una mujer ocupada laboralmente tiene el potencial de decidir cuánto tiempo puede destinar a su familia y a su trabajo, lo que se convierte en una medida de control de natalidad y, por tanto, en una mejora en la calidad de formación y acompañamiento de su núcleo familiar ${ }^{57}$. Pero para alcanzar esto, es necesario que sea valorada en relación con su potencial para aportar capital humano a un mercado laboral, que solo se adquiere mediante capacitación y transferencia de conocimiento.

Lo anterior se debe tener en cuenta como un factor que incide en las tasas de mortalidad infantil de manera positiva, pues puede diseñar el proyecto de sustento de las personas a su cargo. Esto refleja el valor agregado en educación pues permite hacer una proyección de cómo esos bienes tutelados - es decir, los derechos de la mujer y los proyectos de vida de los menores o personas discapacitadas-se verán reflejados en mercados como el laboral. Esto requiere políticas públicas pacientes y sostenibles, que proyecten la valoración de esos resultados agregados a largo plazo y, sobre todo, que estén articuladas con miras a la atención prioritaria de libertades.

Como se puede apreciar, los países en los que la discriminación de la mujer se hace más arraigada, por políticas estatales ${ }^{58}$ o variables culturales y religiosas, tienen mayores niveles de subdesarrollo, lo que coincide con que son los que menos inversión destinan a educación. La inversión en programas de educación desde la temprana edad materializa proyectos de vida al reducir la mortalidad infantil y genera condiciones de desarrollo que se hacen cuantificables en los niveles de productividad que alcanza el mercado laboral, pero

56 N. Gregory Mankiw, Principios de economía, 343, McGraw-Hill, Madrid (2004).

57 Amartya K. Sen, Desarrollo y libertad, capítulo 8: La agencia de las mujeres y el cambio social, 233-249, 239, Planeta, Bogotá (2000).

58 Sen considera que en las políticas estatales de control de natalidad que se aplican de forma coercitiva subyace una política en contra de la libertad de la mujer. El caso paradigmático es el de China, con su política de hogares de un solo niño. Esto crea brechas de desarrollo al restar autonomía a la mujer para decidir el número de miembros de su familia y puede convertirse en un problema de salud pública y discriminación antes del nacimiento, pues en los núcleos familiares se opta por seleccionar como único hijo al niño frente a la niña, lo que incide en prácticas de aborto, generadas por el mismo Estado. Amartya K. Sen, Desarrollo y libertad, capítulo 9: Población, alimentos y libertad, 250-275, Planeta, Bogotá (2000). 
que requiere políticas sostenibles para que puedan medirse a largo plazo. Cuando no se permite la atención de derechos costosos, como la educación, no se garantiza la libertad de optar por un proyecto educativo, lo que se dificulta aún más cuando se reduce la inversión social.

En conjunto, parece que los datos empíricos confirman con rotundidad la relación negativa entre el porcentaje de mujeres que saben leer y escribir y la fecundidad. (...). El hecho de que las mujeres que tienen estudios no estén dispuestas a quedar encadenadas por la continua crianza de hijos contribuye a provocar este cambio. La educación también contribuye a ampliar su horizonte $y$, en un nivel más prosaico, a difundir la información sobre la planificación familiar. Y naturalmente las mujeres que tienen estudios tienden a tener más libertades para ejercer su agencia en las decisiones familiares, incluidas las cuestiones relacionadas con la fecundidad y maternidad ${ }^{5}$.

La capacitación de la mujer, acompañada del acceso a programas de enseñanza en escritura y lectura, así como la expansión de incentivos en programas educativos a menores de edad entre los $5 \mathrm{y}$ 18 años $^{60}$, permite reducir los factores determinantes de la violencia. En sociedades en proceso de desarrollo, hay sectores sociales vulnerables que se convierten en la brecha de pobreza por falta de oportunidades $^{61}$. Una política pública que se dirija a la atención de menores y mujeres, mediante programas de educación, permitirá reducir marginalidad porque capacita para el ejercicio de una actividad laboral en igualdad de condiciones. De esta forma, el acceso a la educación permite reducir la tasa de muertes violentas

59 Amartya K. Sen, Desarrollo y libertad, capítulo 8: La agencia de las mujeres y el cambio social, 233-249, 244, Planeta, Bogotá (2000).

60 Sobre esto puede verse el caso brasileño de los subsidios entregados a familias de escasos recursos por cada hijo que tengan en un programa educativo y los computadores por cada niño en las escuelas públicas. ANDRÉs OPPENHEIMER, ¡Basta de historias! La obsesión latinoamericana con el pasado y las 12 claves del futuro, Random House Mondadori, Debate, Barcelona (2010). Los subsidios escolares de Lula, 266 y Una computadora para cada niño, 306.

61 Recientemente, en Colombia, se han discutido los temas de violencia intrafamiliar, abuso de los menores y violencia contra la mujer. Estos casos están relacionados con la falta de oportunidades laborales, determinadas directamente por la falta de oportunidades de acceso a la educación. La dependencia de la mujer con la figura de autoridad o la necesidad de recurrir a fuentes de financiación fuera de la familia, crea una nueva dependencia, sobre todo en sectores o estratos económicos bajos, que le resta capacidad de decisión ante las necesidades diarias. La respuesta del Estado ha sido la expansión de medidas legislativas y administrativas, como el referendo que promovía la cadena perpetua para abusadores de menores y la ley de cuotas para la mujer. Estos procesos demuestran ser insuficientes e ineficientes por la ausencia de análisis estructural, lo que resulta en un equivocado enfoque de la problemática, cuando se trata de generar independencia financiera. 
porque al educar a las mujeres (potenciales madres) se abren mayores posibilidades de capacitar a los niños, sobre todo, varones en sectores sociales aislados, que son los más propensos a realizar, como jóvenes o adultos, actividades criminales. La relación entre crisis de educación-varones-delincuencia-mortalidad es definitiva al momento de diseñar las políticas públicas. Esta relación tiene diferentes variables respecto a la visión de los varones, pero no aplica de la misma forma en las mujeres. Por regla general, la mujer no participa en la ocurrencia de delitos violentos. Sen da su visión sobre esta panorámica de la siguiente manera:

Algunos han dado una explicación causal según la cual la incidencia de los delitos violentos lleva a mostrar una preferencia mayor por los hijos varones (...), mientras que otros han dado otra explicación según la cual cuando el número de mujeres (menos inclinadas a la violencia) es mayor, la tasa de delincuencia es más baja. También puede haber un tercer factor relacionado tanto con los delitos violentos como con el predominio de los hombres en el cociente de ambos sexos ${ }^{62}$.

Cuando se educa al niño, esto permite expandir su potencialidad y se convierte en un factor determinante del aumento de las tasas de expectativa de vida. Por otra parte, la mujer gana empoderamiento para decidir, a partir de la autonomía económica, el número de miembros de la familia y si opta o no por organizarse como madre, lo que representa sobre todo en sociedades conservadoras, religiosa y culturalmente hablando, liberarse de la dependencia económica y social. Garantizar oportunidades de trabajo a la mujer y a los jóvenes en edad laboral, amplía las oportunidades y dota de capacidad para decidir sobre su libertad sexual y proyecto de vida. En este contexto, la libertad garantizada a la mujer, se convierte en la mejor política de control de natalidad y salubridad pública. Empoderar a la mujer con la facultad de decidir autónomamente la organización de su familia, incidirá directamente en la reducción y control de natalidad sin necesidad de recurrir a métodos coercitivos $^{63}$, lo que incide en la mejora de la calidad de vida. Por lo general, las teorías de economía utilitaria relacionan los índices

62 Amartya K. Sen, Desarrollo y libertad, capítulo 8: La agencia de las mujeres y el cambio social, 233-249, 246, Planeta, Bogotá (2000).

63 Amartya K. Sen, Desarrollo y libertad, capítulo 9: Población, alimentos y libertad, 250-275, Planeta, Bogotá (2000). 
de pobreza como una explicación de la explosión demográfica. Puede que en esto coincidamos parcialmente. Por otra parte, nos apartamos en el sentido de considerar que la solución al problema viene desde políticas públicas sociales que den la oportunidad de ejercer y acceder a bienes y servicios esenciales como resultado de la expresión de las libertades. Tales políticas, como las que desarrollan las acciones afirmativas en pro de la igualdad de la mujer, se convierten en instrumentos que reducen la pobreza y garantizan el desarrollo ${ }^{64}$. Por ejemplo, las políticas de reducción de las tasas de fecundidad, como las que se han adoptado progresivamente en los países nórdicos y algunos países de Asia, generan condiciones ideales para el desarrollo. Estos resultados solo pueden alcanzarse con acceso suficiente a programas de educación básica. Como se puede apreciar, los países de mayores niveles de progreso cuentan con menores tasas de natalidad. La libertad que ganan la mujer, los niños y los jóvenes incide directamente en el aumento de la esperanza de vida. Por otra parte, los países con bajas tasas de esperanza de vida al nacer, como algunas regiones de Suramérica o África, por lo general tienen escenarios de conflictos armados, desatados por problemas de falta de atención de necesidades sociales, conflictos étnicos o religiosos, o guerras civiles internas. Coincidentemente, como lo advertía la figura 5, en estos países la inversión en educación es generalmente baja, pues los procesos armamentistas terminan siendo la prioridad.

Pero esto no es todo. Las anteriores consideraciones están relacionadas con el reconocimiento de autonomía a los grupos de mujeres, jóvenes y niños que tienen acceso a la educación y los resultados en materia de desarrollo que demuestran las políticas educativas. La figura 10, que relaciona la tasa de esperanza de vida, muestra que en países que sufren conflictos armados internos (entre ellos, Colombia), aquella es baja, en comparación con los países desarrollados (Noruega, Dinamarca) o en proceso de desarrollo (Costa Rica), donde la esperanza de vida de las mujeres sigue siendo mayor. Entre los factores que hacen la diferencia, creemos que la no participación de la mujer, como sujeto activo del conflicto, es una de ellas.

64 Amartya K. Sen, Desarrollo y libertad, capítulo 9: Población, alimentos y libertad, 250-275, 262, Planeta, Bogotá (2000). 
El empoderamiento de derechos del que hemos venido hablando, se materializa por medio de la institucionalización o - si se quiere - constitucionalización de políticas educativas entre grupos históricamente marginados, y la inversión del sector público que se destina a educación, representada en el PIB. La educación se convierte en el mejor incentivo para recurrir a los mercados en busca de oportunidades laborales. Este empoderamiento no solo garantiza la capacitación y competitividad de la mujer. Otra variable definitiva para alcanzar niveles de progreso, es cuánto se invierte en educación de niños y jóvenes. Las políticas públicas educativas de menores de edad son garantía de reducción de violencia y, por ende, de tasas de mortalidad. Al retomar las figuras anteriores, si se comparan los países objeto de la muestra, como Israel, Costa Rica o Bangladesh o, incluso, los países nórdicos, no se trata de países con altos niveles de crecimiento económico, como Estados Unidos, China y en los últimos 5 años, Colombia. Esto demuestra que países con menores niveles de desarrollo son propensos a tener mayores niveles de nacimientos que llevan a mayores condiciones de marginalidad, lo que desencadena muertes violentas y altas tasas de mortalidad. Incluso, está medición aplica para países con altos niveles de crecimiento cuyas condiciones de acceso a oferta de bienes esenciales están limitadas para grupos minoritarios, pues no son el objetivo de las políticas clasistas de los gobiernos de turno ${ }^{65}$.

Junto a Amartya Sen, no creemos que por medio de políticas coercitivas, como las adoptadas en China desde la década de los 70, para la restricción de los nacimientos, sea posible garantizar mejores condiciones u oportunidades de acceso a los recursos esenciales y reducir así las condiciones de violencia por el acceso a ellos. Aquí, el tiempo y los recursos que un país destine a la educación de mujeres y niños, incidirá en un sentido progresivo en la reducción de

65 Amartya Sen, La mortalidad como indicador económico, en Primero la gente, 79-120, 110, Amartya Sen \& Bernardo Kliksberg, Deusto, Barcelona (2007). Para el caso, se puede tomar como referencia la tasa de mortalidad en Rusia durante el paso del socialismo al capitalismo en el período de 1980 a 1993 . Aunque no es parte del presente estudio, se puede decir que cuando Rusia alcanzó su "libertad” económica y se convirtió en una de las economías liberales más fuertes de Occidente, en un contexto de relativa paz, esto no trajo la reducción de las tasas de mortalidad, por cuanto las condiciones de pobreza y falta de acceso de las poblaciones y grupos reducidos a los recursos siguieron siendo las mismas que bajo el esquema de la Unión Soviética. 
muertes y el aumento de oportunidades de abrirse camino en las actividades laborales, sociales y económicas.

A pesar del escepticismo inicial respecto a esta cuestión, hoy día está razonablemente claro que la difusión de información y la posibilidad de acceder a servicios de control de natalidad influyen en la fecundidad de las familias en los países que tienen elevada tasa de natalidad y escasos servicios de control de natalidad. Por ejemplo, el brusco descenso de la fecundidad registrado en Bangladesh guarda relación con el movimiento de planificación familiar y, en particular, con el aumento de las facilidades de acceso a la información y a los servicios de planificación familiar. (...) Este logro echa por tierra la creencia de que la gente no aceptará de manera voluntaria la planificación familiar en los países menos desarrollados ${ }^{66}$.

Estos datos permiten contrastar algo que los modelos liberales daban por descartado. Los países con altos niveles de crecimiento económico, como Estados Unidos, superan en tasas de mortalidad a países en proceso de desarrollo, como Singapur y Finlandia, donde no se tienen iguales niveles de PIB o crecimiento económico, pero que han venido adoptando reformas sociales estructurales a los modelos educativos, en el sentido de ampliar el gasto social en educación, y sentar políticas incluyentes en el sector ${ }^{67}$.

\section{Figura 12}

Tasa de mortalidad de menores de 5 años (por cada 1.000 nacimientos), 2012

Fuente: Banco Mundial, http://www.bancomundial.org/

Nota: Por tasa de mortalidad se entiende que por cada 1.000 nacimientos hay la posibilidad de que un bebé muera antes de los 5 años.

La mejora en las condiciones de vida no está determinada por el crecimiento económico amparado en ideologías utilitarias ${ }^{68}$ y reformas institucionales como el Sistema General de Participaciones y la sostenibilidad fiscal, en el caso de Colombia, sino por proyectos de gasto social, cuya finalidad es la inversión en programas de atención

66 Amartya K. Sen, Desarrollo y libertad, capítulo 9: Población, alimentos y libertad, 250-275, 264, Planeta, Bogotá (2000).

67 Andrés OpPEnheImer, ¡Basta de historias! La obsesión latinoamericana con el pasado y las 12 claves del futuro, 63, 91, Random House Mondadori, Debate, Barcelona (2010).

68 Amartya K. Sen, Desarrollo y libertad, capítulo 9: Población, alimentos y libertad, 250-275, 258, Planeta, Bogotá (2000). 
a la población en niveles de pobreza arraigada por falta de acceso a educación, trabajo, salud, vivienda y alimentación.

Respecto al combate de la exclusión por falta de acceso a la educación, la Corte Constitucional había venido definiendo el campo de aplicación del derecho en diferentes áreas de protección que obviamente representan inversión por el Ejecutivo, como la protección que se predica para la educación de las personas en estado de alguna discapacidad o marginalidad, dada la condición de derecho social fundamental de la educación. En los fallos mencionados previamente, es evidente la preocupación de la Corte por elaborar una política intervencionista en el sentido de garantizar condiciones de acceso a sectores esenciales para combatir la exclusión social y la segregación económica, al dar a la gente la capacidad de decidir por su acceso al mercado laboral. Esto ratifica la innecesaria postura de hablar de la gratuidad de la educación en el mercado, porque el problema no es un problema de renta, sino de condiciones de acceso al mercado, en condiciones de favorabilidad e igualdad. En este sentido, los proyectos de inversión social generalmente no reflejan sus resultados en variables de crecimiento económico. En la primera década del siglo XXI, parece que la tendencia mundial de las políticas orientadas hacia la reducción de gasto público, encuentra una limitante en el reconocimiento de las prioridades sociales. No obstante, estas políticas se han convertido en la fuente de reducción de posibilidades de acceso a los mercados ${ }^{69}$ y para nada han permitido la corrección de las brechas de indiferencia de las sociedades modernas ${ }^{70}$.

En el contexto de las crisis se habla de políticas proteccionistas, como si esta protección o forma de restricción del intervencionismo estatal en la economía garantizara el progreso. Las respuestas a las crisis de 1998 y 2008 fueron medidas contrainflacionarias, regulación del sector financiero y reducción del gasto público. Pese a esto, los índices de pobreza, desigualdad y concentración

69 Bernardo Kliksberg, América Latina. El caso de la salud pública, en Primero la gente, 121-186, 136, Amartya Sen \& Bernardo Kliksberg, Deusto, Barcelona (2007).

70 Las lecciones del mundo real saltan a la vista. La política de restricción de inversión social en Grecia, España e Italia, desde 2008, ha desencadenado más que una crisis económica, una crisis social que ha obligado a adoptar políticas de reducción del endeudamiento y el déficit fiscal para buscar la refinanciación de las arcas del Estado y reactivar los mercados laborales que (re)dinamicen las economías. 
de la riqueza se mantuvieron constantes. Se trataba de reformas laborales y ajustes de regulación de los sectores financieros que funcionaban para estabilizar procesos monetarios pero no para garantizar la distribución de riqueza y la apertura de posibilidades que garanticen derechos.

\section{Comentarios finales}

La creencia en modelos económicos de crecimiento, que alcanzaron su auge en los años 80 del siglo XX, espera que en algún momento se garanticen condiciones óptimas de progreso. La visión parecía indicar que los altos niveles de PIB per cápita y la reducción de los niveles de inflación ${ }^{71}$ garantizarían la felicidad de la gente, cuando todo parece indicar que se trata de lo contrario. Condiciones de progreso, que se miden por los resultados en los mercados laborales, se alcanzan con inversión en educación y garantizan niveles de desarrollo que incidirán en niveles de crecimiento. De la educación depende la capacitación, y de esta, la generación de capital humano y, así, la expansión del mercado laboral y de la productividad del país. El caso de la educación de las mujeres es bastante diciente al respecto, como lo comprueba Sen.

Incluso dentro de la familia, las vidas afectadas pueden ser las de los hijos, ya que existen abundantes pruebas de que el aumento del poder de las mujeres dentro de la familia puede reducir significativamente la mortalidad. Y si vamos más allá, la agencia y la voz de las mujeres, en los que influyen la educación y el empleo, pueden influir, a su vez, en la naturaleza del debate público sobre toda una variedad de cuestiones sociales, entre las cuales se encuentran unas tasas de fecundidad aceptables (...) y las prioridades en el terreno del medio ambiente $^{72}$.

El problema parece no solo afectar a la política en educación en gran parte de Latinoamérica. Al respecto, se encuentra el siguiente análisis de Bernardo Kliksberg, siguiendo muy de cerca la línea trazada por Amartya Sen que ha venido siendo planteada aquí, en lo que se refiere al impacto de las reformas económicas y

71 Bernardo Kliksberg, América Latina. El caso de la salud pública, en Primero la gente, 121-186, 121, Amartya Sen \& Bernardo Kliksberg, Deusto, Barcelona (2007).

72 Amartya K. Sen, Desarrollo y libertad, capítulo 8: La agencia de las mujeres y el cambio social, 233-249, 238, Planeta, Bogotá (2000). 
las limitaciones de acceso a los derechos que implican una carga prestacional para el Estado y que resulta pertinente para hacer una reflexión y advertencia sobre la finalidad de las políticas públicas en educación:

En similar sentido plantea Vinod Thomas (2006), director general del Grupo de Evaluación Independiente del Banco Mundial: Ha sido un concepto equivocado la idea de que se puede crecer primero y preocuparse por la distribución después.

Este escenario de desigualdades agudas, persistentes, y de enorme peso en el aumento de la pobreza, en las dificultades para un crecimiento sostenido, y de gran influencia en las carencias que afligen la vida diaria de la mayor parte de la población, es el contexto en que se desenvuelve la salud pública en América Latina. La desigualdad actúa sobre los determinantes de la salud, y es una de las fuerzas más poderosas en la creación de las condiciones propicias para un problema fundamental, la inequidad en salud (... $)^{73}$.

De acuerdo con la reconstrucción histórica que se vio en la primera parte de la investigación ${ }^{74}$, la mayor desatención social y la desprotección de derechos sociales se han producido con mayor vehemencia desde la esfera del Estado, para dar paso a la financiación de proyectos de gobierno con el aumento del déficit fiscal, como los iniciados en la década de 1970, y las políticas de restricción del gasto presupuestal con destino a la inversión social que se hicieron fuertes después de la crisis mundial de $2008^{75}$. Parece

73 Bernardo Kliksberg, América Latina. El caso de la salud pública, en Primero la gente, 121-186, 137, Amartya Sen \& Bernardo Kliksberg, Deusto, Barcelona (2007).

74 La politica en educación, punto I: Reconstrucción histórica de la política económica en Colombia (2014). Disponible en: http://revistas.javeriana.edu.co/index.php/vnijuri/article/view/10171

75 La financiación del proyecto armamentista resulta paradójica, porque en las Fuerzas Militares se ha generado una sistemática violación de los derechos sociales de los militares heridos en actos del servicio. Sentencias del Consejo de Estado: Consejo de Estado, Sección Segunda, Sentencia del 21 de enero de 2010. Consejero ponente Víctor Hernando Alvarado-Ardila. Radicado: 2009-00835-01(AC). Consejo de Estado, Sección Cuarta, Sentencia del 8 de abril de 2010. Consejero ponente Martha Tereza Briceño. Radicado: 2009-00599-01(AC). Consejo de Estado, Sección Primera, Sentencia del 11 de noviembre de 2010. Consejero ponente María Elizabeth García-González. Radicado: 2010-00475-01(AC). En la Corte Constitucional se pueden consultar las sentencias: Corte Constitucional, Sentencia T-275/09, 13 de abril de 2009. Magistrado ponente Mauricio González-Cuervo. Disponible en: http://www.corteconstitucional.gov.co/relatoria/2009/T-275-09.htm. Corte Constitucional, Sentencia T-516/09, 30 de julio de 2009. Magistrado ponente Luis Ernesto Vargas-Silva. Disponible en: http://www.corteconstitucional.gov.co/relatoria/2009/T-516-09.htm. Corte Constitucional, Sentencia T-602/09, 31 de agosto de 2009. Magistrado ponente Gabriel Eduardo Mendoza-Martelo. Disponible en: http://www.corteconstitucional.gov.co/relatoria/2009/T-602-09.htm. Corte Constitucional, Sentencia T-510/10, 17 de junio de 2010. Magistrado ponente Mauricio González-Cuervo. Disponible en: http://www.corteconstitucional.gov.co/relatoria/2010/T-510-10.htm 
que las crisis económicas de los últimos tiempos, sobre todo en los modelos educativos, han sido generadas por las disputas ideológicas de los proyectos económicos. Las peores crisis que acompañan a un modelo económico son aquellas en las que este se convierte en la causa directa de discriminación y exclusión. Desde esta óptica surge una reflexión final. El concepto de pobreza que se había manejado desde la perspectiva de la economía clásica pasa a ser redefinido. Ahora, la pobreza y las condiciones de exclusión, injusticia social y segregación económica pasan a ser concebidas como un todo. Las condiciones de pobreza y de ausencia de un proyecto de vida digno, ahora dejan de ser entendidas como la falta de ingreso o renta baja, sino como la falta de oportunidades de acceso a mercados y al cubrimiento de las necesidades básicas, lo que no está relacionado con ausencia de ingreso pero sí con reducidas tasas de desarrollo económico.

Reformas constitucionales y políticas de Estado que van encaminadas a atacar la pobreza desde la perspectiva clásica de la ausencia de renta menguan la protección y atención a los derechos de contenido social, al limitar el intervencionismo del juez y condicionar sus fallos a las decisiones del administrativo, sin perjuicio de la reducción de autonomía constitucional del primero. Esta limitación del activismo judicial que mostraba la Corte Constitucional ${ }^{76}$, es el objetivo de la política de reduccionismo estatal que se implantó a inicios del siglo XXI mediante las reformas constitucionales, muy al estilo de las políticas conservadoras adoptadas entre 1950 y 1990.

Lo anterior acrecienta el concepto de pobreza porque, al reducirse la inversión y la protección en gasto social en el sector educativo, se crea una barrera de acceso a servicios esenciales. Esto representa un retroceso que se había venido corrigiendo desde el año 2000, en relación con los casos de protección especial de sectores marginados, mediante el activismo judicial y la noción de acciones afirmativas incluyentes. La pobreza, a partir de lo que Sen llama la falta de capacidades, no se combate con políticas de crecimiento económico.

76 La política en educación, Punto I.A, Discusiones sobre crecimiento y desarrollo en el modelo económico del siglo XX. 1936-2013, tabla 1. 1992-2011 (2014). Disponible en: http://revistas. javeriana.edu.co/index.php/vnijuri/article/view/10171 
En materia de educación, queda una reflexión final. Las acciones afirmativas han sido una respuesta contundente del derecho a la crisis económica y asistencial de los derechos sociales en el siglo XXI. Sin embargo, esto parece ser insuficiente por cuanto se trata de combatir un período de crisis económica asentado durante los últimos 32 años, desde la crisis financiera de 1982, en los que la teoría económica prevaleciente tiende a petrificar los procesos de inversión social, por cuanto, tal como lo muestran las gráficas consultadas, no hay un verdadero avance, en el sentido del progreso que aspiraba alcanzar la Constitución en materia de derechos mediante procesos como la descentralización territorial y financiera, o por medio de instituciones como el gasto social. Las reformas constitucionales hablan más de un proceso de legalización de la Constitución, en el que se incluyen reformas para condicionar las políticas de inversión en política económica.

La intervención que proponía la Corte Constitucional en materia educativa, se ha visto reducida por esas reformas constitucionales. En materia de transferencias, esto es verificable porque los avances en cobertura educativa incluyente, tanto de niños y niñas, tienden a ser muy bajos. No obstante, la visión de inclusión y progresismo asistencial, que clama por una economía más ética, que acepte juicios y discusiones morales y que parta de posturas basadas en la compasión y la solidaridad social y económica, como parte del discurso constructivo de una sociedad democrática, como lo propone la teoría de Amartya Sen, ratificada por el activismo de la Corte Constitucional en la protección del derecho a la educación, han dejado marcados los lineamientos para el diseño de políticas públicas educativas incluyentes dirigidas hacia la atención de grupos menos favorecidos. Estos avances, algo aislados, hablan de un progreso en la apertura de oportunidades para sacar de la pobreza a mujeres y niños, y así garantizar la posibilidad de optar por un proyecto decidido por su propio titular. Es decir, un proyecto económico de vida, en el cual la libertad sea, no el resultado final, sino su punto de partida. 


\section{BIBLIOGRAFÍA}

\section{Libros}

Arango-Rivadeneira, Rodolfo, El concepto de los derechos sociales fundamentales, Legis, Bogotá (2005).

Cepeda-Espinosa, Manuel José, Polémicas constitucionales, Legis, Bogotá (2007).

Dworkin, Ronald, El imperio de la justicia, Gedisa, Barcelona (1988).

Ferrari-Quine, César Attilio, Política económica y mercados, Pontificia Universidad Javeriana, Bogotá (2005).

Gómez-Pinto, Luis Ricardo, El juez de las políticas públicas, Grupo Editorial Ibáñez, Pontificia Universidad Javeriana, Bogotá (2012).

GONZÁLEZ-JÁCOME, JoRge, Los debates del pensamiento jurídico colombiano entre 1886 y 1920, Pontificia Universidad Javeriana, Ibáñez, Bogotá (2011).

IbÁÑEZ-NAJAR, Jorge EnRiQue, Estudios de derecho constitucional económico, Javegraf, Bogotá (2001).

Kalmanovitz, Salomón, Economía y nación. Una breve historia de Colombia, Norma, Bogotá (2003).

Kalmanovitz, Salomón, Las instituciones y el desarrollo económico en Colombia, Norma, Bogotá (2001).

Keynes, John Maynard, Teoría general de la ocupación, el interés y el dinero, Fondo de Cultura Económica, FCE, México (1986).

Lerma-Carreño, Carlos Alberto, El derecho a la educación en Colombia, Foro Latinoamericano de Políticas Educativas, FLAPE, Buenos Aires (2007). Disponible en: http://www.redacademica.edu.co/archivos/redacademica/ proyectos/ddhh/autoformacion_ddhh/unidad11/anexo_11-3_el_derecho_a_la_ educacion_en_colombia.pdf

López-Medina, Diego Eduardo, El derecho de los jueces, Legis, Bogotá (2006).

López-Medina, Diego Eduardo; Amaya-González, Renata; Beltrán-Torres, Ana María; Slebi-Asela, María Lorena \& GonzÁlez-Jácome, Jorge, Las fuentes del argumento, Legis, Bogotá (2010).

Mankiw, N. Gregory, Principios de economía, McGraw-Hill, Madrid (2004).

OPPENheImer, ANDRÉs, ¡Basta de historias! La obsesión latinoamericana con el pasado y las 12 claves del futuro, Random House Mondadori, Debate, Barcelona (2010).

Pipitone, Ugo, Ciudades, naciones y regiones. Los espacios institucionales de la modernidad, Fondo de Cultura Económica, FCE, México (2003).

Quinche-Ramírez, Manuel Fernando, Derecho Constitucional Colombiano, Ibáñez, Bogotá (2008).

Rawls, John, Teoría de la justicia, Fondo de Cultura Económica, FCE, México (2010).

Restrepo, Juan Camilo, Derecho presupuestal colombiano, Legis, Bogotá (2007). 
Restrepo, Juan Camilo, Hacienda pública, Universidad Externado de Colombia, Bogotá (2000).

Salazar-Vargas, Carlos, Políticas públicas y think tanks, Konrad Adenauer Stiftung, Bogotá (2008).

Sen, Amartya K., Desarrollo y libertad, Planeta, Bogotá (2000).

Sen, Amartya K., Economía de bienestar y dos aproximaciones a los derechos, Universidad Externado de Colombia, Bogotá (2002).

Sen, Amartya K., El derecho a no tener hambre, Universidad Externado de Colombia, Bogotá (2002).

Sen, Amartya K., La idea de la justicia, Taurus, Bogotá (2010).

Sen, Amartya \& Kliksberg, Bernardo, Primero la gente, Deusto, Barcelona (2007).

\section{Contribuciones en obras colectivas}

Alviar-García, Helena, La búsqueda del progreso en la interpretación de la Constitución de 1991: el caso de la intervención de la Corte en la economía, en: Hacia un nuevo derecho constitucional, 153-180, Daniel Bonilla \& Manuel Iturralde, eds., Universidad de los Andes, Bogotá (2005).

Alviar-García, Helena, Uso y límites de la acción pública de inconstitucionalidad en Colombia, en Teoría constitucional y políticas públicas, bases críticas para una discusión, 477-519, Manuel José Cepeda, Eduardo Montealegre-Lynett \& Alexei Julio-Estrada, coords., Externado de Colombia, Bogotá (2007).

Arango-Rivadeneira, Rodolfo, Introducción, en Tres lustros de jurisprudencia constitucional. Marzo 1992-Febrero 2007. Primer Informe del Observatorio de Justicia Constitucional de la Defensoría del Pueblo, 27-37, tomo 1, Adriana Rosas, coord., Observatorio de Justicia Constitucional, Defensoría del Pueblo, Bogotá (2009).

Fajardo-Glauser, Silvia, Tutela de derechos no enunciados en otros capítulos, en Teoría constitucional y políticas públicas, bases críticas para una discusión, MANUEL José Cepeda, Eduardo Montealegre-Lynett \& Alexei Julio-Estrada, coords., Externado de Colombia, Bogotá (2007).

Ferrari-Quine, César Attilio, Para crecer a tasas asiáticas, en El camino hacia el estado comunitario: tres años de gobierno: evaluación y recomendaciones del Consejo Nacional de Planeación al Plan Nacional de Desarrollo 2002-2006, 87-134, Consejo Nacional de Planeación, Pontificia Universidad Javeriana, Bogotá (2005).

Ferrari-Quine, César Attilio, Precios, competencia y desarrollo económico, en Política económica y economía social de mercado en Colombia, 83-101, Alejandro VivasBenítez, comp., Konrad Adenauer Stiftung, Corporación Pensamiento Siglo XXI, Pontificia Universidad Javeriana, Bogotá. 2006.

GonzÁlez-Borrero, Jorge IvÁn, Acceso igualitario a activos, condición del desarrollo, en Política económica y economía social de mercado en Colombia, 49-56, AlEJANDro Vivas-Benítez, comp., Konrad Adenauer Stiftung, Corporación Pensamiento Siglo XXI, Pontificia Universidad Javeriana, Bogotá. 2006. 
NovoA-Torres, Édgar, Reestructuración, campos jurídicos y Corte Constitucional, en Intelectuales, tecnócratas y reformas neoliberales en América Latina, 347-382, Jairo Estrada-Álvarez, ed., Universidad Nacional de Colombia, Convenio Andrés Bello \& Colciencias, Bogotá (2005).

Peeler, John A., Elite Settlements and Democratic Consolidation: Colombia, Costa Rica, and Venezuela, en Elites and Democratic Consolidation in Latin America and Southern Europe, 81-112, John Higley \& Richard Gunther, eds., Cambridge University Press, Cambridge (1992).

Zafra, Gustavo, Modelo político colombiano y la cuestión social, en Política económica y economía social de mercado en Colombia, Alejandro Vivas-Benítez, comp., Konrad Adenauer Stiftung, Corporación Pensamiento Siglo XXI, Pontificia Universidad Javeriana, Bogotá. 2006.

\section{Revistas}

Benegas-Lynch, Alberto, Bienes públicos, externalidades y los free-riders: el argumento reconsiderado, 71 Estudios Públicos, 203-218 (1998). Disponible en: http://www. hacer.org/pdf/Bienes.pdf

Gómez-Pinto, Luis Ricardo, La política en educación como determinante de desarrollo económico: el contexto histórico sobre la tensión de modelos económicos (I), 128 Vniversitas, 121-152 (2014). Disponible en: http://revistas.javeriana.edu.co/index. php/vnijuri/article/view/10171

Herrera, Martha Cecilia, Historia de la educación en Colombia. La República liberal y la modernización de la educación: 1930-1946, 26 Revista Colombiana de Educación, 97-122 (1993). Disponible en: http://www.pedagogica.edu.co/storage/ rce/articulos/rce26_06ensa.pdf

\section{Tratados internacionales}

Organización de Estados Americanos, OEA, Convención Americana sobre Derechos Humanos o Pacto de San José, CADH, San José, Costa Rica, 7-22 de noviembre de 1969. Disponible en: http://www.oas.org/dil/esp/tratados_B-32_Convencion_ Americana_sobre_Derechos_Humanos.htm

\section{Casos internacionales}

United States Supreme Court, Case of Brown v. Board of Education of Topeka, 47 U.S. 483 (1954), decided May 17, 1954., Case of Brown v. Board of Education of Topeka, 47 U.S. 483 (1954), decided May 17, 1954. Disponible en: http://www. law.cornell.edu/supremecourt/text/347/483 


\section{Normatividad colombiana}

Acto Legislativo 01 de 2001, por medio del cual se modifican algunos artículos de la Constitución Política, 1 de agosto de 2001. Disponible en: http://www. mineducacion.gov.co/1621/articles-90475_archivo_pdf.pdf

Acto Legislativo 04 de 2007, por el cual se reforman los artículos 356 y 357 de la Constitución Política, 11 de julio de 2007. Disponible en: http://www. alcaldiabogota.gov.co/sisjur/normas/Norma1.jsp?i=25671

Acto Legislativo 03 de 2011, por el cual se establece el principio de la sostenibilidad fiscal, 1 de julio de 2011. Disponible en: http://www.alcaldiabogota.gov.co/sisjur/ normas/Norma1.jsp?i $=43214$

Constitución de 1886, 5 de agosto de 1886. Disponible en: http://www.alcaldiabogota. gov.co/sisjur/normas/Norma1.jsp?i=7153

Constitución Política, 4 de julio de 1991. Disponible en: http://www.alcaldiabogota.gov. $\mathrm{co} /$ sisjur/normas/Norma1.jsp?i=4125

Ley 30 de 1992, por la cual se organiza el servicio público de la Educación Superior, 29 de diciembre de 1992, Disponible en: http://www.secretariasenado.gov.co/ senado/basedoc/ley_0030_1992.html

Ley 60 de 1993, por la cual se dictan normas orgánicas sobre la distribución de competencias de conformidad con los artículos 151 y 288 de la Constitución Política y se distribuyen recursos según los artículos 356 y 357 de la Constitución Política y se dictan otras disposiciones, 12 de agosto de 1993. Disponible en: http://www.alcaldiabogota.gov.co/sisjur/normas/Norma1.jsp?i=274

Ley 115 de 1994, por la cual se expide la ley general de educación, 8 de febrero de 1994. Disponible en: http://www.secretariasenado.gov.co/senado/basedoc/ ley_0115_1994.html

Ley 715 de 2001, por la cual se dictan normas orgánicas en materia de recursos y competencias de conformidad con los artículos 151, 288, 356 y 357 (Acto Legislativo 01 de 2001) de la Constitución Política y se dictan otras disposiciones para organizar la prestación de los servicios de educación y salud, entre otros, 21 de diciembre de 2001. Disponible en: http://www.mineducacion.gov.co/1621/ articles-86098_archivo_pdf.pdf

Ley 789 de 2002, por la cual se dictan normas para apoyar el empleo y ampliar la protección social y se modifican algunos artículos del Código Sustantivo de Trabajo, 27 de diciembre de 2002. Disponible en http://www.alcaldiabogota. gov.co/sisjur/normas/Norma1.jsp?i=6778

Ley 1429 de 2010, por la cual se expide la Ley de Formalización y Generación de Empleo, 29 de diciembre de 2010. Disponible en: http://www.alcaldiabogota.gov.co/sisjur/ normas/Norma1.jsp?i=41060

Ley 1473 de 2011, por medio de la cual se establece una regla fiscal y se dictan otras disposiciones, 5 de julio de 2011. Disponible en: http://www.alcaldiabogota.gov. co/sisjur/normas/Norma1.jsp?i=43236 


\section{Jurisprudencia colombiana}

Consejo de Estado, Sección Segunda, Sentencia del 21 de enero de 2010. Consejero ponente Víctor Hernando Alvarado-Ardila. Radicado: 2009-00835-01(AC).

Consejo de Estado, Sección Cuarta, Sentencia del 8 de abril de 2010. Consejero ponente Martha Tereza Briceño. Radicado: 2009-00599-01(AC).

Consejo de Estado, Sección Primera, Sentencia del 11 de noviembre de 2010. Consejero ponente María Elizabeth García-González. Radicado: 2010-00475-01(AC).

Corte Constitucional, Sentencia C-520/94, 21 de noviembre de 1994. Magistrado ponente Hernando Herrera-Vergara. Disponible en: http://www.corteconstitucional.gov. co/relatoria/1994/C-520-94.htm

Corte Constitucional, Sentencia C-559/01, 31 de mayo de 2001. Magistrado ponente Jaime Araújo-Rentería. Disponible en: http://corteconstitucional.gov.co/ relatoria/2001/C-559-01.htm

Corte Constitucional, Sentencia C-150/03, 25 de febrero de 2003. Magistrado ponente Manuel José Cepeda-Espinosa. Disponible en: http://www.corteconstitucional. gov.co/relatoria/2003/c-150-03.htm

Corte Constitucional, Sentencia C-288/12, 18 de abril de 2012. Magistrado ponente Luis Ernesto Vargas-Silva. Disponible en: http://www.corteconstitucional.gov. co/relatoria/2012/C-288-12.htm

Corte Constitucional, Sentencia T-329/97, 11 de julio de 1997. Magistrado ponente Fabio Morón-Díaz. Disponible en: http://www.corteconstitucional.gov.co/ relatoria/1997/T-329-97.htm

Corte Constitucional, Sentencia T-683/02, 22 de agosto de 2002. Magistrado ponente Marco Gerardo Monroy-Cabra. Disponible en: http://www.corteconstitucional. gov.co/relatoria/2002/T-683-02.htm

Corte Constitucional, Sentencia T-899/05, 1 de septiembre de 2005. Magistrado ponente Alfredo Beltrán-Sierra. Disponible en: http://www.corteconstitucional.gov.co/ relatoria/2005/T-899-05.htm

Corte Constitucional, Sentencia T-1015/05, 6 de octubre de 2005. Magistrado ponente Marco Gerardo Monroy-Cabra. Disponible en: http://www.corteconstitucional. gov.co/relatoria/2005/T-1015-05.htm

Corte Constitucional, Sentencia T-886/06, 26 de octubre de 2006. Magistrado ponente Marco Gerardo Monroy-Cabra. Disponible en: http://www.corteconstitucional. gov.co/relatoria/2006/T-886-06.htm

Corte Constitucional, Sentencia T-275/09, 13 de abril de 2009. Magistrado ponente Mauricio González-Cuervo. Disponible en: http://www.corteconstitucional. gov.co/relatoria/2009/T-275-09.htm

Corte Constitucional, Sentencia T-516/09, 30 de julio de 2009. Magistrado ponente Luis Ernesto Vargas-Silva. Disponible en: http://www.corteconstitucional.gov.co/ relatoria/2009/T-516-09.htm

Corte Constitucional, Sentencia T-602/09, 31 de agosto de 2009. Magistrado ponente Gabriel Eduardo Mendoza-Martelo. Disponible en: http://www. 
corteconstitucional.gov.co/relatoria/2009/T-602-09.htm

Corte Constitucional, Sentencia T-510/10, 17 de junio de 2010. Magistrado ponente Mauricio González-Cuervo. Disponible en: http://www.corteconstitucional. gov.co/relatoria/2010/T-510-10.htm

Corte Constitucional, Sentencia T-056/11, 4 de febrero de 2011. Magistrado ponente Jorge Iván Palacio-Palacio. Disponible en: http://www.corteconstitucional.gov. co/relatoria/2011/t-056-11.htm

Corte Constitucional, Sentencia T-139/13, 14 de marzo de 2013. Magistrado ponente Luis Ernesto Vargas-Silva. Disponible en: http://www.corteconstitucional.gov. co/relatoria/2013/t-139-13.htm

Corte Constitucional, Sentencia SU-388/05, 13 de abril de 2005. Magistrado ponente Clara Inés Vargas-Hernández. Disponible en: http://www.corteconstitucional. gov.co/relatoria/2005/SU388-05.htm

\section{Mimeo}

División de Educación y Cultura de la Unidad de Desarrollo Social del Departamento Nacional de Planeación, Características de los docentes y el personal administrativo colombiano en 1995 (mimeo).

\section{Medios de comunicación, prensa}

El dilema de la educación superior: ‘gratuidad o sostenibilidad?, 14 Ámbito Jurídico, 336 (12 de diciembre de 2011-15 de enero de 2012).

\section{Sitios web}

Banco Mundial, http://www.bancomundial.org/ 